\title{
The Benefits of Being Present: Mindfulness and Its Role in Psychological Well-Being
}

\author{
Kirk Warren Brown and Richard M. Ryan \\ University of Rochester
}

\begin{abstract}
Mindfulness is an attribute of consciousness long believed to promote well-being. This research provides a theoretical and empirical examination of the role of mindfulness in psychological well-being. The development and psychometric properties of the dispositional Mindful Attention Awareness Scale (MAAS) are described. Correlational, quasi-experimental, and laboratory studies then show that the MAAS measures a unique quality of consciousness that is related to a variety of well-being constructs, that differentiates mindfulness practitioners from others, and that is associated with enhanced selfawareness. An experience-sampling study shows that both dispositional and state mindfulness predict self-regulated behavior and positive emotional states. Finally, a clinical intervention study with cancer patients demonstrates that increases in mindfulness over time relate to declines in mood disturbance and stress.
\end{abstract}

Many philosophical, spiritual, and psychological traditions emphasize the importance of the quality of consciousness for the maintenance and enhancement of well-being (Wilber, 2000). Despite this, it is easy to overlook the importance of consciousness in human well-being because almost everyone exercises its primary capacities, that is, attention and awareness. Indeed, the relation between qualities of consciousness and well-being has received little empirical attention. One attribute of consciousness that has been much-discussed in relation to well-being is mindfulness. The concept of mindfulness has roots in Buddhist and other contemplative traditions where conscious attention and awareness are actively cultivated. It is most commonly defined as the state of being attentive to and aware of what is taking place in the present. For example, Nyanaponika Thera (1972) called mindfulness "the clear and single-minded awareness of what actually happens to us and in us at the successive moments of perception" (p. 5). Hanh (1976) similarly defined mindfulness as "keeping one's consciousness alive to the present reality" (p. 11).

Recent research has shown that the enhancement of mindfulness through training facilitates a variety of well-being outcomes (e.g.,

Kirk Warren Brown and Richard M. Ryan, Department of Clinical and Social Sciences in Psychology, University of Rochester.

This research was supported in part by a postdoctoral fellowship from the Social Sciences and Humanities Research Council of Canada, by grants from the Russell Sage Foundation and the Society of the Psychological Study of Social Issues to Kirk Warren Brown, and by National Institute of Mental Health Grant 59594 to Richard M. Ryan. We are grateful to Linda Carlson, Ed Deci, Jennifer LaGuardia, Martin Lynch, and Todd Thrash for their helpful comments on previous versions of this article. We also thank D.S. Moskowitz, Joseph Schwartz, Joshua Smyth, and Harry Reis for statistical programming help; Chris Stevens and Bodhin Kjolhede for participant recruitment assistance; and Linda Carlson for collecting the data presented in Study 5.

Correspondence concerning this article should be addressed to Kirk Warren Brown, Department of Clinical and Social Sciences in Psychology, University of Rochester, Meliora Hall, Rochester, New York 14627-0266. E-mail: kirk@psych.rochester.edu
Kabat-Zinn, 1990). To date, however, there has been little work examining this attribute as a naturally occurring characteristic. Recognizing that most everyone has the capacity to attend and to be aware, we nonetheless assume (a) that individuals differ in their propensity or willingness to be aware and to sustain attention to what is occurring in the present and (b) that this mindful capacity varies within persons, because it can be sharpened or dulled by a variety of factors. The intent of the present research is to reliably identify these inter- and intrapersonal variations in mindfulness, establish their relations to other relevant psychological constructs, and demonstrate their importance to a variety of forms of psychological well-being.

\section{THE NATURE OF MINDFULNESS AND MINDLESSNESS}

Several authors (e.g., Averill, 1992; Mayer, Chabot, \& Carlsmith, 1997) have distinguished consciousness from other modes of mental processing-namely, cognition, motives, and emotions - that allow humans to operate effectively. Thus, one can be conscious of thoughts, motives, and emotions as well as sensory and perceptual stimuli. Consciousness encompasses both awareness and attention. Awareness is the background "radar" of consciousness, continually monitoring the inner and outer environment. One may be aware of stimuli without them being at the center of attention. Attention is a process of focusing conscious awareness, providing heightened sensitivity to a limited range of experience (Westen, 1999). In actuality, awareness and attention are intertwined, such that attention continually pulls "figures" out of the "ground" of awareness, holding them focally for varying lengths of time.

Although attention and awareness are relatively constant features of normal functioning, mindfulness can be considered an enhanced attention to and awareness of current experience or present reality. Specifically, a core characteristic of mindfulness has been described as open or receptive awareness and attention (Deikman, 1982; Martin, 1997), which may be reflected in a more 
regular or sustained consciousness of ongoing events and experiences. For example, in speaking with a friend, one can be highly attentive to the communication and sensitively aware of the perhaps subtle emotional tone underlying it. Similarly, when eating a meal, one can be attuned to the moment-to-moment taste experience while also peripherally aware of the increasing feeling of fullness in one's stomach. This is to be contrasted with consciousness that is blunted or restricted in various ways. For example, rumination, absorption in the past, or fantasies and anxieties about the future can pull one away from what is taking place in the present. Awareness or attention can also be divided, such as when people are occupied with multiple tasks or preoccupied with concerns that detract from the quality of engagement with what is focally present. Mindfulness is also compromised when individuals behave compulsively or automatically, without awareness of or attention to one's behavior (Deci \& Ryan, 1980). Finally, mindlessness, which we denote as the relative absence of mindfulness, can be defensively motivated, as when an individual refuses to acknowledge or attend to a thought, emotion, motive, or object of perception. These forms of consciousness thus serve as concrete counterpoints to mindful presence and the attention to current experience within and without oneself that such presence entails.

As presently defined, mindfulness bears some relation to other constructs that have received empirical attention. For example, emotional intelligence, as described by Salovey, Mayer, Goldman, Turvey, and Palfai (1995), includes perceptual clarity about one's emotional states. Insofar as mindfulness involves receptive attention to psychological states, we expect it to be associated with such clarity. In less mindful states, emotions may occur outside of awareness or drive behavior before one clearly acknowledges them. Mindfulness also appears to relate to aspects of the Openness to Experience dimension of personality (Costa \& McCrae, 1992), which involves receptivity to and interest in new experiences. Receptive attention would appear to support the contact with and assimilation of feelings and new ideas, for example. On the other hand, the imagination, fantasy, and aesthetic interest facets of Openness measured in Big Five research do not theoretically relate to mindfulness-mindlessness as presently defined, given the role of cognition in Openness.

Finally, the concept of mindfulness as we describe it bears some relation to earlier groundbreaking work by Langer (1989) and colleagues (e.g., Bodner \& Langer, 2001; Langer \& Moldoveanu, 2000). Langer's formulation includes an open, assimilative "wakefulness" to cognitive tasks and in this has some overlap with the current formulation. However, Langer's formulation emphasizes active cognitive operations on perceptual inputs from the external environment, such as the creation of new categories and the seeking of multiple perspectives. The present definition emphasizes an open, undivided observation of what is occurring both internally and externally rather than a particular cognitive approach to external stimuli.

Mindfulness can also be distinguished from various forms of self-awareness that have received considerable attention over the past 30 years. Most prominently, Duval and Wicklund's (1972) theory of objective self-awareness, Buss's (1980) self-consciousness theory, and Carver and Scheier's (1981) control theory all define self-awareness in terms of knowledge about the self. For example, private self-consciousness represents a disposition to be highly aware of internal states (e.g., Fenigstein, Scheier, \& Buss,
1975). However, this form of awareness is defined by its focus rather than by its quality. Thus, high private self-consciousness may reflect preoccupation with internal states or an open receptivity to them. Recent research has, in fact, uncovered two factors in this construct, internal state awareness and self-reflectiveness (Cramer, 2000; Trapnell \& Campbell, 1999). The former represents sensitivity to ongoing psychological processes, a construct that has greater conceptual overlap with mindfulness. Even more distinct from mindfulness is public self-consciousness, the tendency to be concerned about the self as perceived by others, which may detract from present awareness. Several other approaches to the measurement of self-awareness have also been developed, including self-monitoring (Snyder, 1974) and reflection (Trapnell \& Campbell, 1999).

Although distinct in the content that each examines, all the forms of self-awareness discussed above reflect cognitive operations on aspects of the self through self-examination, processes collectively termed reflexive consciousness (Baumeister, 1999; Bermúdez, 1998). Mindfulness directed inward differs from these approaches in that its mode of functioning is perceptual or "prereflexive," operating on, rather than within, thought, feeling, and other contents of consciousness. Rather than generating mental accounts about the self, mindfulness "offer[s] a bare display of what is taking place” (Shear \& Jevning, 1999, p. 204). Thus, whereas the modes of reflexive consciousness noted above concern the focus of cognitive operations, mindfulness concerns the quality of consciousness itself and, except for the inverse relation to public self-consciousness noted above, is theorized to have little or no inherent relation to reflexive thought.

\section{MINDFULNESS AND WELL-BEING}

William James (1911/1924) had great interest in the study of consciousness, but he was not sanguine about the usual state of consciousness of the average person, stating, "Compared to what we ought to be, we are only half awake" (p. 237). This perspective has been shared by contemporary scholars (e.g., Tart, 1994). Mindfulness captures a quality of consciousness that is characterized by clarity and vividness of current experience and functioning and thus stands in contrast to the mindless, less "awake" states of habitual or automatic functioning that may be chronic for many individuals. Mindfulness may be important in disengaging individuals from automatic thoughts, habits, and unhealthy behavior patterns and thus could play a key role in fostering informed and self-endorsed behavioral regulation, which has long been associated with well-being enhancement (Ryan \& Deci, 2000). Further, by adding clarity and vividness to experience, mindfulness may also contribute to well-being and happiness in a direct way. In this section, we offer theoretical and empirical support for both of these hypothesized effects.

Theorists from many schools of personality and psychotherapy have discussed the importance of observant, open awareness and attention in the optimization of self-regulation and well-being (see reviews in Brazier, 1995; Martin, 1997). In the psychoanalytic tradition, for example, free association represents a receptive awareness wherein attention "evenly hovers" over the psychological landscape (Freud, 1912/1963). In other dynamic and humanistic traditions, awareness is thought to enable the identification of needs, conflicts, and existential concerns. Most notably, Perls 
(1973) saw the healthy organism as forming clear and vital gestalts or perceptions that emerge in states of relaxed attention. Bringing awareness to bear on facets of experience that have been alienated, ignored, or distorted has been theorized to convert "hidden subjects" into "conscious objects" that can be differentiated from, transcended, and integrated into the self (Wilber, 2000). Finally, theorists in the cognitive tradition have discussed the importance of attention to gathering factual information on behavior or subjective experience as a first step in making health-enhancing behavior changes (Safran \& Segal, 1990).

Several theories of self-regulation discuss the place of awareness and attention in the maintenance and enhancement of psychological and behavioral functioning. One of these is selfdetermination theory (SDT; Deci \& Ryan, 1985; Ryan \& Deci, 2000), which posits that an open awareness may be especially valuable in facilitating the choice of behaviors that are consistent with one's needs, values, and interests (Deci \& Ryan, 1980). In contrast, automatic or controlled processing often precludes considerations of options that would be more congruent with needs and values (Ryan, Kuhl, \& Deci, 1997). In this sense, then, mindfulness may facilitate well-being through self-regulated activity and fulfillment of the basic psychological needs for autonomy (self-endorsed or freely chosen activity), competence, and relatedness (Hodgins \& Knee, 2002). That is, awareness facilitates attention to prompts arising from basic needs, making one more likely to regulate behavior in a way that fulfills such needs.

Not all self-regulatory processes require conscious awareness and attention to operate smoothly, and a substantial portion of day-to-day behavior has been thought to occur automatically or mindlessly (Bargh, 1997; Deci \& Ryan, 1980; Tart, 1994). Thinkers have long argued over the merits and demerits of such behavior (Maddux, 1997), which is defined by the lack of intentional or conscious effort. Although a pragmatic view argues that automaticity saves time and frees the mind for more important tasks, others argue that such automatic thought and behavior patterns may have problematic consequences. For example, Baumeister, Heatherton, and Tice (1994) reviewed evidence showing that the deployment of conscious attention can override unwanted responses, and such deployment is linked to well-being in cognitive, emotional, and behavioral domains.

There are also many instances where attentional sensitivity to psychological, somatic, and environmental cues, a key component of mindfulness, is crucial to the operation of healthy regulatory processes (Brown, 1998; cf. Waldrup, 1992). Indeed, cybernetic theories, such as Carver and Scheier's (1981) control theory, propose that attention is key to the communication and control processes that are thought to underlie the regulation of behavior. Biofeedback research has long shown that attention can be a key component in reducing unhealthy somatic conditions or symptoms of illness (e.g., Basmajian, 1989). The process of disregulation can occur when signals are ignored or suppressed, as happens, for example, when painkillers, alcohol, or drugs are taken to selfmedicate. When disregulation of this kind occurs, attention is required to reestablish communication between elements of a system (e.g., mind and body, or thought and behavior) before wellness can return (G. E. Schwartz, 1984). Disregulation may also occur when somatic and other signals brought to awareness are then cognitively exaggerated, as may happen in panic states, for example (Clark, 1986). In contrast, mindfulness involves per- ceiving stimuli simply "as they are." To date, the most direct evidence for the benefits of mindful awareness and attention has come from research demonstrating that mindfulness training is related to positive psychological and physical outcomes (e.g., Kabat-Zinn, 1990; Shapiro, Schwartz, \& Bonner, 1998). However, the role of mindfulness per se in well-being outcomes has yet to be examined.

A direct route through which mindfulness may enhance wellbeing is its association with higher quality or optimal moment-tomoment experiences. A recent experiment by LeBel and Dubé (2001) found that individuals whose attention was focused on the sensory experience of eating chocolate reported more pleasure than individuals engaged in a distraction task while eating chocolate. More broadly, research has found that intrinsically motivated and flow activities, which are characterized by engagement with and attention to what is occurring, yield considerable enjoyment and a felt sense of vitality (Csikszentmihalyi, 1990; Deci \& Ryan, 1985)

\section{THE PRESENT RESEARCH}

Mindfulness is inherently a state of consciousness. Although awareness and attention to present events and experiences are given features of the human organism, these qualities can vary considerably, from heightened states of clarity and sensitivity to low levels, as in habitual, automatic, mindless, or blunted thought or action (Wallace, 1999). This suggests (a) that because of inherent capability, discipline, or inclination, individuals may differ in the frequency with which they deploy attention and awareness and also (b) that there are intraindividual variations in mindfulness. This research thus investigates mindfulness as an attribute that varies both between and within persons and examines the significance of both kinds of variation for well-being.

A first step in this research was the measurement of mindfulness. In the first portion of this article, we describe the development, reliability, and validity of a new instrument, the Mindful Attention Awareness Scale (MAAS), which assesses individual differences in the frequency of mindful states over time. We hypothesized that this disposition would share variance with other awareness constructs while also tapping a unique experience that distinguishes it from other psychological phenomena. The MAAS is focused on the presence or absence of attention to and awareness of what is occurring in the present rather than on attributes such as acceptance, trust, empathy, gratitude, or the various others that have been associated with mindfulness (e.g., Shapiro \& Schwartz, 1999). This present-centered attention-awareness is, in our view, foundational to mindfulness and thus is our starting point in research. To further establish the validity of the MAAS, we tested whether the scale differentiates persons engaged in the cultivation of mindfulness from others.

The central purpose of this research program was to examine empirical links between mindfulness and well-being. In attempting to establish empirically the self-regulatory nature of mindfulness, we first assessed whether mindfulness is associated with greater awareness of internal states using a lab-based paradigm in which the role of mindfulness as a predictor of the degree of relation between an implicit and self-reported (explicit) indicator of emotional well-being was assessed. We also examined concurrent associations of the MAAS with measures of both self-regulation 
and well-being. Using experience-sampling techniques, we then tested predictive relations between both trait and MAAS-derived state measures of mindfulness and indicators of both self-regulated (and, specifically, autonomous) functioning and emotional wellbeing. Finally, the importance of mindfulness to well-being was tested within an intervention paradigm in which changes in MAAS-measured mindfulness were used to predict changes in mood and stress among a sample of patients with cancer who received training in mindfulness as the central element of a stressreduction program.

A detailed investigation of mindfulness as an individual difference characteristic has a number of benefits, not the least of which is that it allows examination of the role of this phenomenon in positive psychological experience. More fundamentally, the study of mindfulness may help to widen the window into the study of consciousness, how it can be "structured" (Mayer, 2000), and its role in human functioning.

\section{THE MEASUREMENT OF MINDFULNESS: MAAS CONSTRUCTION, FACTOR ANALYSES, AND RELIABILITY ASSESSMENT}

\section{Preliminary Item Selection Procedures}

Inspiration for scale items came from several sources: our personal experience and knowledge of mindfulness (and mindlessness), published writings on mindfulness and attention, and existing scales assessing conscious states of various kinds. Items were drafted to reflect the experience of mindfulness and mindlessness in general terms as well as in specific day-to-day circumstances, including variations in awareness of and attention to actions, interpersonal communication, thoughts, emotions, and physical states.

We began with a pool of 184 items, approximately equally split between those reflecting direct and indirect assessment of mindfulness, where the latter reflected absence of mindlessness. Item reduction was done in an iterative fashion across five stages. In all stages, several exclusion criteria were used. Because our intent was to capture the central, subjective experience of mindfulness as present attention and awareness, items containing attitudinal components (e.g., patience, trust, acceptance) were excluded, as were those referring to motivational intent (the "why" of awareness or attention). Items reflecting potential consequences of mindfulness (e.g., calmness, emotional or physical well being) were also excluded. Finally, because we sought to develop a scale for a general adult population, we excluded statements that implied or assumed refined levels of consciousness (e.g., highly sensitive awareness) or required a specialized vocabulary.

In the first stage of item reduction, we applied these exclusion criteria to eliminate a number of items through dialogue. A shorter list was then submitted to nine experienced practitioners of mindfulness (i.e., "experts") who were provided with our exclusion criteria and a brief working definition of our construct. They then rated the adequacy of each item as an assessment tool, using a 5-point Likert scale (very good, good, fair, poor, very poor). The $V$ statistic was then used as the criterion for item retention (Aiken, 1985, 1996). This statistic is a content validity coefficient designed for use with a small number of ordinal validity ratings. Only items that were rated highly and consistently across raters $(p<.05)$ were retained. To ensure that the remaining items would be clear, understandable, and applicable to the life experiences of the average adult, eight faculty and graduate students in psychology rated these items, and the $V$ statistic was again used to retain items. The resulting items were rated by yet another team of six faculty and graduate students, and their feedback was used to eliminate ambiguous items and revise others.

The 55 items that remained from this final round of ratings were included in several pilot studies with undergraduates. Items with non-normal (skewed or kurtotic) distributions were eliminated as were those showing less than a full range of response on a 6-point Likert scale. Twenty-four items were retained for further analysis.

\section{Exploratory Factor Analysis}

To explore the factor structure of the derived scale, it was completed by a sample of 313 undergraduates in return for extra course credit (Sample A, Table 1). Because the item pool was small and each item normally distributed, the maximum-likelihood method of parameter estimation was chosen (Cudeck, 2000). The Kaiser measure of sampling adequacy was .89. Inspection of eigenvalues and the scree plot revealed a marked gap between the first and remaining factors (Factor 1 eigenvalue $=7.85$; Factor 2 eigenvalue $=.66$ ). The first factor accounted for $95 \%$ of the total variation across factors. Exploratory factor analysis using the principal-factors method of estimation also showed a strong single-factor solution and almost identical factor loadings. Thus, only those items loading on the first factor were retained. On the factor derived from maximum-likelihood estimation, the average factor loading was .52 .

Table 2 presents the 15 -item MAAS that was used in subsequent studies. Inspection of the item-level statistics indicates that all but two items loaded above .30. Items 5 and 13 loaded above .25 and were retained because both added substantive breadth to the scale (cf. Basilevsky, 1994; Tabachnick \& Fidell, 1996). In the analysis of broadband constructs such as the present one, smaller factor loadings are not atypical (Hoyle, 2000). ${ }^{1}$

MAAS respondents indicate how frequently they have the experience described in each statement using a 6-point Likert scale from 1 (almost always) to 6 (almost never), where high scores reflect more mindfulness. In an attempt to control for socially desirable responding, respondents are asked to answer according to what "really reflects" their experience rather than what they think their experience should be. The items are distributed across cognitive, emotional, physical, interpersonal, and general domains. It is noteworthy that statements reflecting high levels of attention and awareness were eliminated by both item raters and factor analysis (because of very low loadings). Why direct endorsements of mindfulness were eliminated is subject to speculation, but as our item raters noted during scale construction, it is relatively easy (if

\footnotetext{
${ }^{1}$ Several analyses were conducted to test the impact of these lower loading items on the psychometric properties of the scale. Deletion of the two items made only a tiny difference to the internal consistency of the scale and to the fit indices of the confirmatory factor analysis (CFA) reported below. In the cross-validation sample of adults, these two items loaded higher on the factor than in the student sample used for exploratory analysis. Thus, the decision to retain them in the scale was supported on both substantive and statistical grounds.
} 
Table 1

Sample Characteristics (Scale Construction and Study 1)

\begin{tabular}{|c|c|c|c|c|c|c|c|}
\hline \multirow[b]{2}{*}{ Characteristic } & \multicolumn{7}{|c|}{ Sample } \\
\hline & A & B & $\mathrm{C}$ & $\mathrm{D}$ & $\mathrm{E}$ & $\mathrm{F}$ & G \\
\hline Location & $\mathrm{UR}^{\mathrm{a}}$ & $\mathrm{UR}^{\mathrm{b}}$ & HWS $^{\mathrm{c}}$ & $\mathrm{UR}^{\mathrm{d}}$ & $\mathrm{UR}^{\mathrm{e}}$ & Community $^{\mathrm{f}}$ & National $^{\mathrm{g}}$ \\
\hline Cronbach's alpha & .84 & .82 & .80 & .82 & .87 & .86 & .87 \\
\hline$N$ & 313 & 327 & 207 & 187 & 145 & 74 & 239 \\
\hline Age range (years) & $18-23$ & $17-28$ & $17-23$ & $17-23$ & $18-32$ & $18-62$ & $18-77$ \\
\hline Age mean (years) & 19.5 & 19.6 & 19.0 & 19.7 & 19.8 & 37.6 & 43.3 \\
\hline Female $(\%)$ & 66 & 64 & 62 & 62 & 64 & 55 & 66 \\
\hline Caucasian (\%) & 73 & 77 & 85 & 77 & 63 & 88 & 93 \\
\hline Asian (\%) & 15 & 10 & 3 & 9 & 19 & 3 & 1 \\
\hline African American (\%) & 3 & 5 & 5 & 4 & 9 & 3 & 1 \\
\hline Hispanic $(\%)$ & 4 & 3 & 3 & 4 & 4 & 0 & 2 \\
\hline Native American (\%) & 0 & 1 & 1 & 0 & 0 & 4 & 0 \\
\hline Other ethnicity (\%) & 5 & 5 & 5 & 6 & 5 & 3 & 3 \\
\hline
\end{tabular}

Note. $\quad \mathrm{UR}=$ University of Rochester; HWS $=$ Hobart and William Smith Colleges

${ }^{\mathrm{a}}$ UR, Spring 2000. ${ }^{\mathrm{b}}$ UR, Fall 2000 and Spring 2001. ${ }^{\mathrm{c}}$ HWS, Fall 2000 and Spring 2001. ${ }^{\mathrm{d}}$ UR, Fall 2001. ${ }^{\mathrm{e}}$ UR, Spring 2002. ${ }^{\mathrm{f}}$ Rochester local community, Fall 1999 and Spring 2000. ${ }^{\mathrm{g}}$ U.S.-wide mail-out survey, Fall 2000 and Spring 2001.

incorrect) to endorse being attentive and aware. In fact, inspection of the means and distributions of these items revealed that many had low values on the Likert scale and marked skewness. Further, statements reflecting less mindlessness are likely more accessible to most individuals, given that mindless states are much more common than mindful states (McIntosh, 1997; Varela, Thompson, \& Rosch, 1991). As Packer (2002) noted in discussing present awareness, "It is easier to point out what is absent in [it]" (p. 137). Thus, indirect items may be more "diagnostic" than direct claims to mindfulness. This approach has also been used to assess medical

Table 2

Means, Standard Deviations, Factor Loadings, and Item-Total Correlations for the Mindful Attention Awareness Scale

\begin{tabular}{lllll}
\hline \multicolumn{1}{c}{ Scale item } & $M$ & $S D$ & $\mathrm{~F}$ & $\mathrm{I}-\mathrm{T}$ \\
\hline $\begin{array}{l}\text { 1. I could be experiencing some emotion and not be conscious of it until } \\
\text { some time later. }\end{array}$ & 4.02 & 1.12 & .46 & .45 \\
2. I break or spill things because of carelessness, not paying attention, or & 4.13 & 1.47 & .45 & .42 \\
$\quad$ thinking of something else. & & & & \\
3. I find it difficult to stay focused on what's happening in the present. & 3.80 & 1.23 & .51 & .49 \\
4. I tend to walk quickly to get where I'm going without paying attention & 3.41 & 1.27 & .45 & .39 \\
$\quad$ to what I experience along the way. & & & & \\
5. I tend not to notice feelings of physical tension or discomfort until they & 3.83 & 1.22 & .27 & .25 \\
$\quad$ really grab my attention. & & & & \\
6. I forget a person's name almost as soon as I've been told it for the first & 3.40 & 1.54 & .33 & .31 \\
time. & & & & \\
7. It seems I am "running on automatic" without much awareness of what & 3.72 & 1.24 & .78 & .72 \\
$\quad$ I'm doing. & & & & \\
8. I rush through activities without being really attentive to them. & 3.81 & 1.11 & .74 & .67 \\
9. I get so focused on the goal I want to achieve that I lose touch with & 3.74 & 1.15 & .38 & .38 \\
$\quad$ what I am doing right now to get there. & & & & \\
10. I do jobs or tasks automatically, without being aware of what I'm doing. & 3.70 & 1.20 & .69 & .61 \\
11. I find myself listening to someone with one ear, doing something else at & 3.52 & 1.16 & .55 & .49 \\
the same time. & & & & \\
12. I drive places on "automatic pilot" and then wonder why I went there. & 4.36 & 1.42 & .62 & .57 \\
13. I find myself preoccupied with the future or the past. & 2.66 & 1.03 & .28 & .26 \\
14. I find myself doing things without paying attention. & 3.66 & 1.14 & .77 & .69 \\
15. I snack without being aware that I'm eating. & 4.11 & 1.42 & .47 & .41 \\
\hline
\end{tabular}

Note. All scores are based on Sample A data $(N=313)$. Items were introduced by the following: "Below is a collection of statements about your everyday experience. Using the 1-6 scale below, please indicate how frequently or infrequently you currently have each experience. Please answer according to what really reflects your experience rather than what you think your experience should be." The accompanying 6-point scale was 1 = almost always, $2=$ very frequently, $3=$ somewhat frequently, $4=$ somewhat infrequently, $5=$ very infrequently, and $6=$ almost never. $\mathrm{F}=$ factor loadings; $\mathrm{I}-\mathrm{T}=$ item-total correlations. 
treatment adherence (e.g., Haynes et al., 1980). However, it is important to demonstrate that the indirect approach to mindfulness measurement has the same conceptual meaning as a direct approach, and we empirically examined the conceptual equivalence of the two approaches in Study 1. We also compared their convergent, discriminant, and criterion validity.

\section{Confirmatory Factor Analysis (CFA): College Student and General Adult Samples}

\section{Student Sample}

We performed a CFA of the single-factor model revealed by exploratory analysis on data from a new sample of 327 university students (Sample B in Table 1), using maximum-likelihood estimation and the AMOS 4.0 program (Arbuckle \& Wothke, 1999). The fit indices of the model indicated that the correspondence between the single-factor model and the sample covariance matrix was satisfactory, $\chi^{2}(90, N=327)=189.57$ (goodness-of-fit index $[\mathrm{GFI}]=.92$, comparative fit index $[\mathrm{CFI}]=.91$, index of fit $[\mathrm{IFI}]$ $=.91$, parsimony-adjusted comparative fit index $[\mathrm{PCFI}]=.78$, root-mean-square error of approximation [RMSEA] $=.058$ ). All 15 items of the scale were significantly related to the latent factor (all $p \mathrm{~s}<.001$ ). The internal consistency (alpha) was .82 .

\section{General Adult Sample}

Cross-validation of a model in a second, independent sample is recommended to increase the likelihood that the model holds in a population (Schumacker \& Lomax, 1996). To test whether the factorial model would hold among noncollege adults, it was evaluated in a U.S.-wide sample of 239 adults (Sample G, Table 1) ranging in age from 18 to 77 years $(M=43.27)$. These individuals, who collectively were drawn from 48 U.S. states, completed the MAAS as part of a mail-out survey study (Brown \& Kasser, 2002). We used the AMOS 4.0 program (Arbuckle \& Wothke, 1999) to perform the CFA using maximum-likelihood estimation. The fit with the single factor model was satisfactory, $\chi^{2}(90, N=239)=$ $179.14(\mathrm{GFI}=.91, \mathrm{CFI}=.92, \mathrm{IFI}=.92, \mathrm{PCFI}=.79, \mathrm{RMSEA}=$ $.065)$. All scale items were significantly related to the latent factor $(p s<.001)$. The sample alpha was .87 .

\section{Test-Retest Reliability and Agreement}

The temporal stability of the scale was examined in an independent sample of 60 introductory psychology students over a 4-week period (26 men, 34 women; mean age 19 years). To assess testretest reliability and agreement, a variance components analysis was done using SAS PROC MIXED (SAS Institute, 1992, 1997). The intraclass correlation (equivalent to a Pearson $r$ with two measures) was $.81(p<.0001)$. Another index of stability is test-retest score agreement, that is, whether individuals generally receive the same scale scores over repeated assessment (Dawis, 2000). The analysis found that the Time 1 (3.78) and Time 2 (3.77) mean scale scores were not significantly different, $t(59)=.11, n s$. As a final note, we add that in all subsequent samples, we confirmed the MAAS factorial structure and reliability. For brevity we do not further report these statistics.

\section{STUDY 1. CORRELATIONS WITH OTHER MEASURES}

Any attempt to establish the viability of an individual difference measure must show that it is, as Mayer (2000) succinctly noted, "similar enough to other [concepts] to be recognizable, but different enough to be worth studying" (p. 49). Study 1 had two primary purposes: to establish the convergent and discriminant validity of the MAAS and to examine the relations between MAAS-measured mindfulness and a variety of indicators of well-being. As part of this second purpose, we also assessed the incremental validity of the scale. A final purpose of this study was to test the differential utility of the MAAS, which takes an indirect-item approach to measuring mindfulness, to a direct-item approach to measuring mindfulness.

Regarding the first aim, our focus was on scales said to measure the propensity to be aware of specific events or types of experience, whether in the internal or external world. Scales that might tap receptive and clear awareness-for example, emotional intelligence and openness to experience-we expected to relate positively to the MAAS. We also expected moderate convergence with the only existing scale of mindfulness-mindlessness known to us, namely Bodner and Langer's (2001) recently developed measure. A number of scales have also been developed to tap dispositional differences in reflexive consciousness - that is, the tendency to engage in self-examination, reflection, introspection, and related cognitive activities. Some of these traits, like public selfconsciousness and self-monitoring, involve an evaluation or filtering of experiences with reference to the self. We anticipated that mindfulness would show null or negative relations to all such measures. Finally, we expected that mindfulness would be unrelated to the trait of absorption (Tellegen, 1982), a propensity to enter trancelike states of consciousness, which represents being "out of touch" with what is presently occurring.

Regarding the second aim, the present study examined relations between the MAAS and a number of well-being measures. As specified in the introduction, we theorize that mindfulness facilitates self-regulation, psychological health, and enriched momentto-moment experience. Thus, we expected that the MAAS would be related to a variety of indicators of well-being, as manifested in cognitive, emotional, motivational, and physical health functioning. Given our conceptualization of mindfulness as a distinct construct, we also expected that the MAAS would retain its associations with well-being after controlling for the effects of other, related constructs.

Finally, the section of this article entitled THE MEASUREMENT OF MINDFULNESS: MAAS CONSTRUCTION, FACTOR ANALYSES, AND RELIABILITY ASSESSMENT offers some justification for the MAAS's indirect-item approach to the measurement of mindfulness. This study empirically examined whether the scale is generally equivalent to a direct-item approach in the assessment of mindfulness, measured in terms of the magnitude of correlation between the MAAS and an alternative, directitem version of the scale. We also examined the convergent, discriminant, and criterion validity of the MAAS versus this alternate scale.

This study includes six samples, comprising a total of 1,253 participants. Rather than present these samples in separate studies, we summarize our findings in four parts. First, we present findings 
concerning the distinctiveness and overlap of the MAAS with other measures of psychological dispositions and modes of functioning. Second, we present correlations of the MAAS with numerous indices of well-being. Third, we present incremental validity findings on the MAAS. And fourth, we present correlational results comparing the MAAS to an alternate measure.

\section{Method}

\section{Participants}

Samples A-F are described in Table 1. Participants in Samples A-E were students taking psychology courses who received extra course credit for participation. Sample F comprised adults drawn from a northeastern U.S. community (see Study 4 for recruitment details). Participants in all samples completed measures in a single session. Group sizes in Samples A-E ranged from 5 to 25 persons, and in Sample F, groups ranged from 1 to 15 persons.

\section{Materials}

\section{Convergent and Discriminant Scales}

NEO Personality Inventory (NEO-PI) and NEO Five-Factor Inventory (NEO-FFI) Openness to Experience (Costa \& McCrae, 1992). This Big Five personality scale measures openness to ideas, values, aesthetics, emotions, fantasy, and actions. High scorers report a receptivity to novel experiences and actions and a high frequency of, and interest in, imaginative and reflective thought.

Trait Meta-Mood Scale (TMMS; Salovey et al., 1995). This measure of emotional intelligence taps individual differences in attention to feelings (attention), the clarity of experience of these emotions (clarity), and beliefs about prolonging pleasant mood states and ending unpleasant states (repair).

Mindfulness/Mindlessness Scale (MMS; Bodner \& Langer, 2001). The MMS assesses individual differences in the propensity to achieve mindful states, defined as the awareness of behavioral routines, a questioning of their efficacy, and active consideration of alternative behaviors. Its 21 items assess four components: Flexibility, Novelty Seeking, Novelty Producing, and Engagement.

Self-Consciousness Scale (SCS; Fenigstein et al., 1975). This well-known 23-item measure has three subscales. Private Self-Consciousness assesses the tendency to reflect upon oneself, fantasize, and attend to one's moods, motives, and cognitive processes. Recent work indicates that two factors may underlie this subscale: self-reflectiveness and internal state awareness (e.g., Cramer, 2000). The subscale Public Self-Consciousness measures the tendency to view oneself from the perspective of the social world and reflects a concern for one's appearance, social behavior, and the impression one makes upon others. Relatedly, the subscale Social Anxiety taps shyness, embarrassment, and anxiety in social situations.

Rumination-Reflection Questionnaire (RRQ; Trapnell \& Campbell, 1999). The 12-item Reflection subscale of the RRQ assesses "intellectual self-attentiveness" through items tapping the tendency to explore, analyze, and contemplate the self. The 12-item Rumination subscale measures "ruminative self-attention," the tendency to dwell on, rehash, or reevaluate events or experiences.

Self-Monitoring Scale-Revised (Snyder \& Gangestad, 1986). This widely researched 18-item scale assesses the tendency to observe and control expressive behavior and self-presentation in accordance with situational cues to social appropriateness.

Need for Cognition (Cacioppo, Petty, \& Kao, 1984). This 18-item scale measures individual differences in engagement and enjoyment of "effortful cognitive endeavors." High scorers endorse items reflecting interest in thinking, complex problem solving, and intellectual tasks.
Absorption (Tellegen, 1982). This 34-item scale assesses a disposition to enter transient altered states of consciousness characterized by a "restructuring" of the experienced self and world. Either dissociation or integration of the self may be experienced by high scorers.

Other scales. The tendency to respond in a socially desirable manner was also assessed, using two well-known indices: the Marlowe-Crowne Social Desirability Inventory (Crowne \& Marlowe, 1960) and the Minnesota Multiphasic Personality Inventory (MMPI) Lie Scale (Hathaway \& McKinley, 1989).

\section{Well-Being Scales}

We also used a number of measures reflecting various aspects of well-being.

Traits and attributes. The Neuroticism scales from the NEO-PI and NEO-FFI (Costa \& McCrae, 1992) assessed dispositional anxiety, hostility, depression, impulsiveness, and vulnerability. Self-esteem was measured with both the 10-item Multidimensional Self-Esteem Inventory (O'Brien \& Epstein, 1988) Self-Worth subscale and the Rosenberg Self-Esteem Scale (Rosenberg, 1965). Optimism was assessed using the Life Orientation Test (Scheier \& Carver, 1985)

Emotional disturbance. Depressive symptoms were specifically assessed using both the 20-item Center for Epidemiological StudiesDepression (CES-D) scale (Radloff, 1977) and the 20-item Beck Depression Inventory (BDI; Beckham \& Leber, 1985). Anxiety was measured using the 20-item State-Trait Anxiety Inventory (STAI; Spielberger, 1983) and the 9-item Profile of Mood States (POMS) Anxiety subscale (McNair, Lorr, \& Droppleman, 1971). Reports on both depression and anxiety were made over the past week or past month, depending on the sample.

Emotional-subjective well-being. Both the valence (hedonic tone) and arousal dimensions of affective experience were assessed. Pleasant and unpleasant affective tone were measured using the 9-item scale derived by Diener and Emmons (1984). The 20-item Positive and Negative Affect Schedule (PANAS; Watson, Clark, \& Tellegen, 1988) assessed affective arousal. Reports were made on affective experience over the past week or month. Life satisfaction was assessed using the 15-item Temporal Life Satisfaction Scale (Pavot, Diener, \& Suh, 1998).

Eudaimonic well-being. Self-actualization was measured using the Measure of Actualization of Potential (Lefrançois, Leclerc, Dubé, Hébert, \& Gaulin, 1997). To test the hypothesis that MAAS would predict greater autonomy, competence, and relatedness we used the relevant subscales from Ryff's (1989) Personal Well-Being Scales. The seven-item Subjective Vitality Scale (Ryan \& Frederick, 1997) assessed the extent to which individuals felt energized and vital over the past week or month.

Physical well-being. We assessed physical well-being using a measure of common physical symptoms adapted from Larsen and Kasimatis (1991), the Hopkins Symptom Checklist Somatization scale (Derogatis, Lipman, Rickels, Uhlenhuth, \& Covi, 1974), and a self-report of medical health visit frequency over the past 21 days.

\section{Results}

\section{Convergent and Discriminant Correlations}

Correlations of the MAAS with other measures assessed are shown in Table 3. As predicted, the MAAS was correlated at a moderate level with emotional intelligence. It was most strongly related to clarity of emotional states but also with mood repair and, to a lesser degree, attention to emotions. The MAAS showed modest positive correlations with NEO-PI Openness to Experience and NEO-FFI Openness to Experience, and was specifically related to the Feelings, Actions, Ideas, and Values subscales on the NEO-PI, which more strongly reflect attentiveness and receptivity 
Table 3

Correlations of the Mindful Attention Awareness Scale With Other Scales: Convergent and Discriminant Validity (Study 1)

\begin{tabular}{|c|c|c|}
\hline Scale & Sample(s) & Correlation(s) \\
\hline NEO-PI Openness to Experience & A & $.18 * *$ \\
\hline Fantasy & A & -.07 \\
\hline Aesthetics & $\mathrm{A}$ & .10 \\
\hline Feelings & A & $.17 * *$ \\
\hline Actions & $\mathrm{A}$ & $.20 * * *$ \\
\hline Ideas & A & $.17 * *$ \\
\hline Values & A & $.15^{* *}$ \\
\hline NEO-FFI Openness to Experience & $\mathrm{D}, \mathrm{E}$ & $.12, .19 *$ \\
\hline Trait Meta-Mood Scale & $\mathrm{A}, \mathrm{D}, \mathrm{E}$ & $.46 * * * *, .42 * * * *, .37 * * * *$ \\
\hline Clarity & $\mathrm{A}, \mathrm{D}, \mathrm{E}$ & $.49 * * * *, .45 * * * *, .50 * * * *$ \\
\hline Attention & $\mathrm{A}, \mathrm{D}, \mathrm{E}$ & $.19 * * *, .17 *, .13$ \\
\hline Repair & $\mathrm{A}, \mathrm{D}, \mathrm{E}$ & $.37 * * * *, .33 * * * *, .25 * *$ \\
\hline Mindfulness/Mindlessness Scale & $\mathrm{D}, \mathrm{E}$ & $.31 * * * *, .33 * * * *$ \\
\hline Flexibility & $\mathrm{D}, \mathrm{E}$ & $.002, .24 * *$ \\
\hline Novelty Seeking & $\mathrm{D}, \mathrm{E}$ & $.30 * * *, .29 * * *$ \\
\hline Novelty Producing & $\mathrm{D}, \mathrm{E}$ & $.23^{* *}, .26^{* * *}$ \\
\hline Engagement & $\mathrm{D}, \mathrm{E}$ & $.39 * * * *, .33 * * * *$ \\
\hline \multicolumn{3}{|l|}{ Self-Consciousness Scale } \\
\hline Private Self-Consciousness & $\mathrm{A}, \mathrm{D}, \mathrm{E}, \mathrm{F}$ & $.03, .03, .05,-.05$ \\
\hline Self-Reflectiveness & $\mathrm{A}, \mathrm{D}, \mathrm{E}, \mathrm{F}$ & $-.13^{*},-.12,-.12,-.19$ \\
\hline Internal State Awareness & $\mathrm{A}, \mathrm{D}, \mathrm{E}, \mathrm{F}$ & $.23^{* * * *}, .17 *, .22 * *, .18$ \\
\hline Public Self-Consciousness & $\mathrm{A}, \mathrm{D}, \mathrm{E}, \mathrm{F}$ & $-.14 *,-.15^{*},-.02,-.18$ \\
\hline Social Anxiety & $\mathrm{A}, \mathrm{D}, \mathrm{E}, \mathrm{F}$ & $-.36 * * * *,-.19 * *,-.33 * * * *,-.29 * *$ \\
\hline \multicolumn{3}{|l|}{ RRQ } \\
\hline Reflection & $\mathrm{A}, \mathrm{D}, \mathrm{E}$ & $.06, .16^{*}, .20 *$ \\
\hline Rumination & $\mathrm{B}, \mathrm{D}, \mathrm{E}$ & $-.39 * * * *,-.29 * * * *,-.38 * * * *$ \\
\hline Self-Monitoring & $\mathrm{B}$ & -.03 \\
\hline Need for Cognition & $\mathrm{C}$ & $.19 * *$ \\
\hline Absorption & $\mathrm{C}$ & $-.15^{*}$ \\
\hline
\end{tabular}

Note. $\quad$ Ns for Samples A, B, C, D, E, and F are 313, 327, 207, 187, 145, and 74, respectively. NEO-PI = NEO Personality Inventory; NEO-FFI = NEO Five-Factor Inventory; RRQ = Reflection Rumination Questionnaire. $* p<.05$. *** $p<.01$. *** $p<.001$. ***** $p<.0001$.

to experience and behavior than the Fantasy and Aesthetics subscales. The MMS (Bodner \& Langer, 2001) was, as expected, correlated with the MAAS. Befitting our theory, the MAAS was most strongly related to mindful engagement. It was correlated to a lesser degree with both novelty seeking and producing, and was unrelated to cognitive flexibility.

As already noted, several scales measure the use of cognitive processes in service of self-examination and reflection on the self. The MAAS was expected to show little or no relation to these measures. As Table 3 shows, there was no correlation with Private Self-Consciousness. However, in line with theoretical expectation, the MAAS was correlated with the internal state awareness aspect of this measure. Although significant, this correlation was modest, perhaps in part because of the poor internal consistency of this subscale (Creed \& Funder, 1998). There were also expectable negative relations to both Public Self-Consciousness and Social Anxiety. Also as predicted, the MAAS was unrelated to SelfMonitoring. Regarding the RRQ, the MAAS was unrelated to Reflection and inversely related to Rumination. A small though significant correlation with the Need for Cognition was found, indicating that mindfulness does not preclude the enjoyment of intellectual activity. Absorption was weakly and inversely related to the MAAS, as expected. Turning finally to social desirability, the MAAS showed positive correlations with the Marlowe-
Crowne in two studies (Samples D and E: $r \mathrm{~s}=.24$ and $.28, p \mathrm{~s}<$ $.001)$, but it was unrelated to the MMPI Lie scale ( $r \mathrm{~s}=.10$ and .03 , $n s)$.

\section{Well-Being Correlations}

Table 4 presents correlations between the MAAS and wellbeing scales. Among the "Big Five" personality traits, neuroticism has been consistently related to poorer psychological well being. The MAAS was moderately related to lower levels of this trait. Across the six facets of this measure, the MAAS was most strongly and inversely related to Depression, Self-Consciousness, and Angry Hostility and less strongly, though still significantly, to Impulsiveness.

The MAAS was related to other indicators of well being, both positive and negative, in consistently expected directions. The MAAS was inversely related to CES-D and BDI measures of depression and STAI and POMS measures of anxiety. Regarding affect, the MAAS was positively related to pleasant hedonic tone and PANAS-measured positive affectivity in two samples of undergraduates and a sample of adults; it was negatively related to unpleasant tone and PANAS negative affectivity. Along with affect, a primary component of subjective well-being is life satisfaction (Diener, Suh, Lucas, \& Smith, 1999). In both college 
Table 4

Correlations of the Mindful Attention Awareness Scale With Dispositional and State Scales

Measuring Psychological Well-Being (Study 1)

\begin{tabular}{ccc}
\hline Scale & Sample(s) & Correlation(s) \\
\hline
\end{tabular}

Traits and attributes

\begin{tabular}{l} 
NEO-PI Neuroticism \\
Anxiety \\
Angry Hostility \\
Depression \\
Self-Consciousness \\
Impulsiveness \\
Vulnerability \\
NEO-FFI Neuroticism \\
MSEI Self-Esteem \\
Rosenberg Self-Esteem \\
LOT Optimism \\
\hline
\end{tabular}

$\begin{array}{ll}\mathrm{A} & -.56 * * * * \\ \mathrm{~A} & -.34 * * * * \\ \mathrm{~A} & -.41 * * * * \\ \mathrm{~A} & -.53 * * * * \\ \mathrm{~A} & -.45 * * * * \\ \mathrm{~A} & -.29 * * * * \\ \mathrm{~A} & -.47 * * * * \\ \mathrm{D}, \mathrm{E} & -.33^{* * * *},-.56 * * * * \\ \mathrm{~B} & .36 * * * * \\ \mathrm{D}, \mathrm{E} & .39 * * * *, .50 * * * * \\ \mathrm{D}, \mathrm{E} & .27 * * * *, .34 * * * *\end{array}$

\begin{tabular}{lll}
\hline & \multicolumn{2}{c}{ Emotional disturbance } \\
CES-D Depression & $\mathrm{B}$ & $-.37 * * * *$ \\
BDI Depression & $\mathrm{D}, \mathrm{E}$ & $-.41 * * *,-.42 * * * *$ \\
STAI Anxiety & $\mathrm{B}$ & $-.40^{* * * * *}$ \\
POMS Anxiety & $\mathrm{D}, \mathrm{E}$ & $-.26 * *,-.42 * * * *$ \\
\hline
\end{tabular}

Emotional-subjective well-being

\begin{tabular}{llc} 
Pleasant Affect & A, B, D, E, F & $.16 * *, .31 * * * *, .35 * * *, .40 * * * *, .29 * *$ \\
Unpleasant Affect & A, B, D, E, F & $-.37 * * * *,-.33 * * * *,-.34 * * *,-.42 * * * *,-.39 * * *$ \\
PANAS Positive Affect & B, D, E & $.30^{* * * *}, 33^{* * * *}, .39 * * * *$ \\
PANAS Negative Affect & B, D, E & $-.39 * * *,-.39 * * * *,-.43 * * * *$ \\
Life Satisfaction & B, F & $.26 * * *, .37 * * *$ \\
\hline
\end{tabular}

Eudaimonic well-being

\begin{tabular}{lll} 
Vitality & $\mathrm{A}, \mathrm{B}, \mathrm{F}$ & $.40^{* * * *}, .35^{* * * *}, .46 * * * *$ \\
MAP Self-Actualization & $\mathrm{B}$ & $.43^{* * * *}$ \\
Autonomy & $\mathrm{B}, \mathrm{F}$ & $.34 * * *, .37 * * *$ \\
Competence & $\mathrm{B}, \mathrm{F}$ & $.39 * * *, .68 * * * *$ \\
Relatedness & $\mathrm{B}, \mathrm{F}$ & $.31 * * * * .28 *$ \\
\hline
\end{tabular}

Physical well-being

\begin{tabular}{lll}
$\begin{array}{l}\text { Reported physical } \\
\text { symptoms }\end{array}$ & $\mathrm{B}, \mathrm{F}$ & $-.25 * * * *,-.51 * * * *$ \\
$\begin{array}{l}\text { HSCL Somatization } \\
\begin{array}{c}\text { Medical visit frequency, } \\
\text { past } 21 \text { days }\end{array}\end{array}$ & $\mathrm{A}, \mathrm{F}$ & $-.40 * * *,-.42 * * *$ \\
& $\mathrm{~F}$ & $-.32 * *$ \\
\hline
\end{tabular}

Note. Ns for Samples A, B, C, D, E, and F are 313, 327, 207, 187, 145, and 74, respectively. NEO-PI = NEO Personality Inventory; NEO-FFI = NEO Five-Factor Inventory; MSEI = Multidimensional Self-Esteem Inventory; LOT $=$ Life Orientation Test CES-D $=$ Center for Epidemiologic Studies Depression Scale; BDI = Beck Depression Inventory; STAI $=$ State-Trait Anxiety Inventory; POMS = Profile of Mood States; PANAS = Positive and Negative Affect Schedule; MAP = Measure of Actualization of Potential; HSCL = Hopkins Symptom Checklist.

$* p<.05 . \quad * * p<.01 . \quad * * * p<.001 . \quad * * * * p<.0001$.

students and adults, the MAAS was positively associated with this variable. Self-esteem scores on both the Multidimensional SelfEsteem Inventory and the Rosenberg measures were higher among those scoring higher on the MAAS. In three samples, the MAAS was associated with higher levels of subjective vitality. Greater self-actualization was also associated with higher mindfulness scores. Finally, in line with our SDT-based hypotheses, the MAAS was related to autonomy, competence, and relatedness fulfillment.

Although our primary interest in this article is relations between the MAAS and psychological well-being, because physical health is known to be influenced by psychological states, we assessed whether the MAAS was related to both subjective and objective indicators of physical health. In both college and community adult samples, the MAAS was inversely related to self-reported physical symptoms, particularly in the adult sample, where symptoms may be more salient. However, self-reported symptoms may have a somatization component - that is, they can reflect a tendency to experience distress in terms of physical complaints. The MAAS was inversely related to somatization in the two samples. Finally, in the adult community sample, the MAAS was inversely related 
to the number of visits made to medical professionals over the past 21 days.

\section{Incremental Validity}

We examined whether the correlations found between the MAAS and a number of well-being variables would remain significant after controlling for the effects of a number of constructs that were shown to be related to the MAAS and that themselves have been associated with various well-being indicators in past research. The MAAS was shown to bear only small to moderate relations to existing measures of dispositional self-awareness. However, these latter measures have themselves been shown to relate to well-being. Private self-consciousness appears to intensify existing positive and, especially, negative affect (Fejfar \& Hoyle, 2000). It has also been associated with lower self-esteem (Fejfar \& Hoyle, 2000), negative mood states (Flory, Raikkonen, Matthews, \& Owens, 2000), anxiety (Davis \& Franzoi, 1999), and depression (Davis \& Franzoi, 1999). Rumination has been associated with depression (e.g., Nolen-Hoeksema, Morrow, \& Fredrickson, 1993), anxiety, and negative affect (Trapnell \& Campbell, 1999). The disposition to regulate one's emotional states (emotional intelligence) has been associated with more positive affect, lower levels of depression (Salovey et al., 1995), and lower anxiety (Goldman, Kraemer, \& Salovey, 1996). The traits neuroticism and extraversion have been strongly associated with negative and positive psychological well-being (Diener et al., 1999). Although not directly relevant to this research, extraversion was related to the MAAS in this study (Samples D and E: $r \mathrm{~s}=.19$ and .22 , respectively; $p s<.01)$. Also, given that the MMS is the only other instrument known to assess "mindfulness" (though defined differently) and showed some relation to the MAAS, we controlled for its effects in testing MAAS-well-being relations. Finally, it is important to control for the effects of social desirability, given both its relation to the MAAS and its positive relation to subjective well-being (Diener, Sandvik, Pavot, \& Gallagher, 1991).

Incremental validity was assessed using combined data from Samples D and E. We used the Rosenthal (1991) meta-analytic approach to apply Fisher's (1928) $r$-to- $z$ transformation to the correlation coefficients from each study and then weight them by their respective study degrees of freedom before calculating mean effect sizes. These effect sizes were then converted back to Pearson $r$ values. Table 5 presents the mean zero-order correlation of the MAAS with a number of well-being variables that are often used as dependent variables in social, personality, and health research. Also presented are the mean partial correlations of the MAAS with the dependent variables after controlling for the effects of private self-consciousness, rumination, emotional intelligence, neuroticism, extraversion, and social desirability.

Table 5 shows that all the correlations between the MAAS and the well-being variables remained significant when controlling for each of the covariates examined. The most notable reductions in correlation magnitude were found when neuroticism was controlled for, particularly when related to anxiety, depression, and unpleasant affect. Other sizable though isolated reductions in correlation magnitude were found in predictable places, given past research, as when controlling for rumination in the relation of the MAAS with negative mood states. Several covariates, including social desirability, made little difference to the MAAS-well-being relations.

\section{Comparison of Indirect and Direct Measures of Mindfulness}

To form an alternate, direct measure of mindfulness, we rephrased 13 of the 15 MAAS items to reflect direct statements. For example, MAAS Item 3 (see Table 2), "I find it difficult to stay focused on what's happening in the present," became "I find it easy to stay focused on what's happening in the present." Rephrasings were done to follow the original wording of each item as closely as possible. Items 2 and 12 (see Table 2) could not be rephrased in a way that preserved the content, so these were retained in original form and reverse scored. Exploratory factor analysis of this scale using data from Sample E $(N=145)$ uncovered a single-factor structure, as in the MAAS. Cronbach's alpha was .81.

The correlation between the MAAS and the alternate scale was .70 , providing evidence that the two scales generally measured the

Table 5

Correlations of the Mindful Attention Awareness Scale With Well-Being Variables Before and After Controlling for Other Constructs (Study 1)

\begin{tabular}{|c|c|c|c|c|c|c|c|c|}
\hline \multirow[b]{2}{*}{ Scale } & \multirow[b]{2}{*}{$\begin{array}{l}\text { Zero-order } \\
\text { correlation }\end{array}$} & \multicolumn{7}{|c|}{ MAAS controlling for } \\
\hline & & Rum & $\operatorname{PrSC}$ & TMMS & MMS & $\mathrm{N}$ & $\mathrm{E}$ & $\begin{array}{c}\text { Social } \\
\text { desirability }\end{array}$ \\
\hline BDI Depression & $-.40 * * * *$ & $-.29 * * * *$ & $-.44 * * * *$ & $-.32 * * * *$ & $-.36^{* * * *}$ & $-.16^{* * *}$ & $-.38 * * * *$ & $-.34 * * * *$ \\
\hline POMS Anxiety & $-.34 * * * *$ & $-.22 * * * *$ & $-.35 * * * *$ & $-.27 * * * *$ & $-.31 * * * *$ & $-.12 *$ & $-.32 * * * *$ & $-.28 * * * *$ \\
\hline Pleasant Affect & $.38 * * * *$ & $.30 * * * *$ & $.37 * * * *$ & $.24 * * * *$ & $.30 * * * *$ & $.20 * * *$ & $.32 * * * *$ & $.35 * * * *$ \\
\hline Unpleasant Affect & $-.38 * * * *$ & $-.28 * * * *$ & $-.39 * * * *$ & $-.30 * * * *$ & $-.35 * * * *$ & $-.14^{* *}$ & $-.36 * * * *$ & $-.33 * * * *$ \\
\hline PANAS Positive Affect & $.36 * * * *$ & $.30 * * * *$ & $.37 * * * *$ & $.25 * * * *$ & $.25 * * * *$ & $.23 * * * *$ & $.31 * * * *$ & $.33 * * * *$ \\
\hline PANAS Negative Affect & $-.41 * * * *$ & $-.33 * * * *$ & $-.44 * * * *$ & $-.35 * * * *$ & $-.40 * * * *$ & $-.22 * * * *$ & $-.39 * * * *$ & $.38 * * * *$ \\
\hline Rosenberg Self-Esteem & $.44 * * * *$ & $.38 * * * *$ & $.44 * * * *$ & $.32 * * * *$ & $.34 * * * *$ & $.25 * * * *$ & $.42 * * * *$ & $.41 * * * *$ \\
\hline
\end{tabular}

Note. $\quad N=332$ (Samples D and E; see Table 1). MAAS = Mindful Attention Awareness Scale; Rum = Rumination; PrSC = Private self-consciousness; TMMS = Trait Meta-Mood Scale; MMS = Mindfulness/Mindlessness Scale; N = NEO Five-Factor Inventory (NEO-FFI) Neuroticism; E = NEO-FFI Extraversion; Social desirability = Marlowe-Crowne Social Desirability Scale; BDI = Beck Depression Inventory; POMS = Profile of Mood States; PANAS $=$ Positive and Negative Affect Schedule.

$* p<.05 . \quad * * p<.01 . \quad * * * p<.001 . \quad * * * * p<.0001$. 
same construct. To assess comparative validity, the correlations of the two scales with other measures were computed using Sample E data. The pattern of correlations was as follows, with MAAS correlations given first and the alternate scale correlations given second: NEO-FFI Openness (.19, .21), Trait Meta-Mood Scale emotional intelligence $(.37, .34)$, MMS mindfulness $(.33, .44)$, SCS Private Self-Consciousness (.05, .06), SCS Public SelfConsciousness $(.01, .07)$, SCS Social Anxiety $(-.33,-.26)$, RRQ Reflection (.20, .20), RRQ Rumination (-.39, -.25), NEO-FFI Neuroticism (-.56, -.45$)$, BDI depression $(-.42,-.32)$, POMS Anxiety $(-.42,-.32)$, pleasant affect $(.40, .33)$, unpleasant affect $(-.42,-.26)$, PANAS Positive Affect $(.39, .36)$, PANAS Negative Affect $(-.37,-.27)$, Rosenberg self-esteem $(.43, .41)$, Life Orientation Test optimism $(.34, .23)$, Marlowe-Crowne desirability $(.28, .32)$, and MMPI Lie $(.03, .02)$. These comparisons show that the MAAS and its alternate had very similar relations to measures used to assess convergent and discriminant validity in this study, although the alternate scale showed more variance overlap with the MMS measure of mindfulness. On measures used to assess criterion validity, the two scales consistently showed the same directions of effect. However, the MAAS often showed stronger relations in expected directions, with some differences in correlation magnitude of 10 points or more. ${ }^{2}$

\section{Discussion}

The pattern of correlations described in this section supports, first, the convergent and discriminant validity of the MAAS in a way consistent with our theory and hypotheses. Although the scale converges with several measures of psychological awareness, the relations are moderate at best, indicating that the scale is tapping a distinct construct. The scale was weakly related or unrelated to a number of popular measures of reflexive consciousness. Overall, the pattern of associations indicates that higher scorers on the MAAS tend to be more aware of and receptive to inner experiences and are more mindful of their overt behavior. They are more "in tune" with their emotional states and able to alter them, and they are more likely to fulfill basic psychological needs. Conversely, such individuals are less likely to be self-conscious, socially anxious, and ruminative than low scorers and are also slightly less likely to enter absorptive states of consciousness. They are generally not more likely to be reflective or to engage in self-scrutiny but appear to value intellectual pursuits slightly more than lower scorers. The MAAS was modestly correlated with one measure of social desirability, the Marlowe-Crowne, and unrelated to a second, namely the MMPI Lie scale. The first result suggests that self-presentation concerns may affect MAAS scores, but it may also reflect the greater attention to personal conduct that the Marlowe-Crowne taps. The incremental validity results indicated that the MAAS-well-being relations cannot be explained by social desirability. Also noteworthy in this regard is the absence of a positive association between the MAAS and both public selfconsciousness, reflecting a concern over how others view one, and self-monitoring, which measures the tendency to self-present to meet social demands.

The correlations of the MAAS with various well-being measures supported a primary hypothesis of this research program, namely that mindfulness is associated with greater well-being. The MAAS was related to lower neuroticism, anxiety, depression, unpleasant affect, and negative affectivity. Conversely, the MAAS was associated with higher pleasant affect, positive affectivity, vitality, life satisfaction, self-esteem, optimism, and self-actualization. It also was related to higher autonomy, competence, and relatedness - the basic needs specified within SDT.

Incremental validity results lent further support to the unique role of mindfulness in well-being. When a range of covariates was controlled for, the MAAS retained sizable correlations across a variety of well-being indicators. Notably, however, the relations between mindfulness and several well-being variables were markedly attenuated when the effects of neuroticism were controlled for. Two points are worth noting in this regard. First, the most sizable decrements in correlation magnitude occurred when incremental relations to depression and anxiety were tested, but both are considered components of neuroticism (see Table 1). Neuroticism is also intimately linked with negative affect (Diener et al., 1999). Thus, the fact that neuroticism captured a sizable proportion of the explained variance in these variables is expectable, particularly given the moderately strong inverse relation between NEOassessed neuroticism and the MAAS found in this study. Second, and equally important, although mindfulness and neuroticism were placed in competition with each other in these analyses, the inverse relation between them is, in fact, meaningful. That is, neuroticism, including worry, (public) self-consciousness, and other features can preclude mindfulness; conversely, the inculcation of awareness of self and others, as is theorized to happen in many forms of psychotherapy, for example, may lead to a reduction in neurotic tendencies. It is in this sense that we consider neuroticism a well-being variable to which mindfulness is meaningfully related (see Table 4). Thus, although neuroticism accounted for a sizable proportion of the shared well-being variance in the incremental analyses, it is unsurprising that a dispositional well-being variable would be strongly related to other, state-level well-being variables. The fact that the MAAS still accounted for variance in all of the well-being measures after controlling for neuroticism supports its utility.

A final important set of findings from this study showed that operationalization of mindfulness taken by the MAAS was highly related to an alternative operationalization that used scale items reflecting direct endorsement of mindfulness. This suggests that direct and indirect assessments of mindfulness tap the same construct. Although the two scales showed mostly equivalent convergent and discriminant validity, the MAAS was more strongly related to a variety of criterion measures of well-being. These findings lend further support to the approach taken by the MAAS to measure the mindfulness construct and examine its role in psychological well-being.

Collectively, these findings indicate that MAAS-measured mindfulness bears broad and inclusive relations to well-being. The

\footnotetext{
${ }^{2}$ Other alternate scale versions, using items representing more balanced distributions of direct and indirect items, were also assessed. Each also showed a single-factor structure and acceptable internal consistency, although slightly lower than the MAAS. As could be expected, the correlation between the MAAS and these other scales was even stronger than with the alternate scale presented here. However, the same general comparative pattern of convergent, discriminant, and criterion validity results was found.
} 
results are made more interesting by the fact that the MAAS does not contain well-being-related content. Indeed, the concept of mindfulness itself is devoid of motivational and attitudinal components that could be construed as predispositions toward wellbeing enhancement. The diversity of well-being constructs with which the MAAS is associated suggests a number of avenues that social, personality, and health research can take to explore the impact that this form of consciousness has on psychological well-being.

\section{STUDY 2. GROUP DIFFERENCES IN MINDFULNESS}

As part of our thesis that mindfulness is an individual difference characteristic, we hypothesized that the MAAS would reliably distinguish between individuals who have taken on the practice of developing greater awareness and attentional capacity and members of the general adult population. One group of individuals known to actively cultivate mindfulness is that of persons engaged in meditative practices. Among students of Zen, for example, a central practice involves training the mind to become attentive to and aware of all that is taking place in the present moment-in one's mind, body, and surroundings. A primary intent of such practice is to become mindful in all spheres of day-to-day life (Goldstein, 1987). The present study examined the known group validity of the MAAS. Also examined were correlates of higher MAAS scores within a Zen sample, the intent of which was to gain insight into specific aspects of practice that may promote mindfulness.

\section{Method}

\section{Participants and Procedure}

Scores from two samples were compared. Individuals from the community membership rolls of a Zen center located in Rochester, New York were selected on the basis of a matching strategy. An investigator naive to other data randomly selected, on a 1:1 basis, persons from that list who were matched in gender and age ( \pm 2 years) with 74 Rochester generalcommunity adults (Sample F; see Table 1 and recruitment details in Study 4). A packet, which included a cover letter, the MAAS, and a brief survey concerning relevant practices, was mailed to the 74 Zen center "matches." The cover letter promised a $\$ 2$ donation to the center's retreat center building fund for every packet returned. The practice-related survey asked whether the individual currently had a meditation practice, the duration of practice history, and the amount of time currently meditating (per day, week, month, etc.). It also asked to what extent the individual perceived that he or she carried the meditative practice into daily life (rated on a 7-point scale from $1=$ not at all to $7=$ very $m u c h$ ). A total of 50 packets (68\% response rate) were returned. Analyses are based on the two matched samples of 50 persons, each composed of 21 men and 29 women (mean age $=41.08 ;$ range $22-62$ years)

\section{Results and Discussion}

A $t$ test of the difference between MAAS scale scores of the Zen practitioner group $(M=4.29, S D=0.66)$ and the comparison group $(M=3.97, S D=0.64)$ was significant, $t(98)=2.45, p<$ .05 (Cohen's $d=.50$ ). Among the 50 Zen participants, 42 were currently practicing meditation at the time of the study. When we compared scale scores between this "active" group and their matched comparisons, the difference was more pronounced
( $M=4.38, S D=0.65$, and $M=3.95, S D=0.61$, respectively), $t(82)=3.09, p<.005(d=.68)$. Within the active Zen sample, the MAAS was correlated with the extent to which individuals perceived that their meditative practice was carried over into daily life $(r=.47, p<.005)$. The amount of time currently practicing meditation was not related to the scale score $(p>.05)$. However, the number of years of practice was positively related to the MAAS $(r=.36, p<.05)$.

These results indicate that the MAAS is sensitive to individual differences in mindfulness and suggest that the higher scores among those consciously practicing this skill are due to such training. It is possible that such elevated scores represent an inherent predisposition in some individuals that draws them to a center where the qualities of attention and awareness are valued. However, the fact that scores were higher among those center members actively practicing meditation weighs against this interpretation, as does the fact that years of practice was related to higher MAAS scores. The sensitivity of the MAAS to individual differences based on mindfulness training suggests that the scale may have application in clinical settings where the qualities associated with mindfulness are actively cultivated (e.g., Kabat-Zinn, 1990). In fact, Study 5 will test the utility of the MAAS in a clinical mindfulness-training context.

\section{STUDY 3. SELF-CONCORDANCE THROUGH MINDFULNESS}

A key facet of the construct of mindfulness is the capacity for self-awareness; that is, highly mindful individuals are theorized to be more attentive to and aware of internal (psychological and physical) constructions, events, and processes than are less mindful individuals. Indeed, we and others have argued that effective self-regulation depends on this capacity for self-insight (e.g., G. E. Schwartz, 1984). The present study was designed to test, within a laboratory setting, whether MAAS-measured mindfulness is associated with greater self-awareness in relation to well-being using awareness of implicit emotional states as a model.

An explosion of research over the past decade has highlighted a distinction between implicit and explicit psychological processes. Implicit processes, also called indirect, automatic, intuitive, and unconscious, are those that become active without conscious choice, effort, or intention (Bargh, 1997). Explicit processes, in contrast, are consciously activated and guided. Priming and implicit classification tasks have revealed the implicit or automatically activated aspect of a number of social and personality phenomena, including attitudes, self-esteem, and motives (see Bargh \& Ferguson, 2000; Greenwald \& Banaji, 1995; and Wilson, Lindsey, \& Schooler, 2000).

An important point of discussion in this area of research is whether and how individuals can be aware of implicit constructs and processes (e.g., Wilson et al., 2000). One way in which such awareness could be demonstrated would be through concordance, such that responses on an explicit measure of a psychological construct match those of the implicit counterpart. Research to date has shown evidence of little or no concordance between explicit and implicit measures in some domains (e.g., self-esteem) and moderately strong relations between the two kinds of measures in others (e.g., gender self-concept; Greenwald \& Farnham, 2000). 
Given such variable associations, investigators have begun to search for moderating variables.

Several factors have been hypothesized to explain the extent to which individuals' explicit reports show concordance with the parallel implicit construct or process (e.g., see Schultheiss \& Brunstein, 1999). Among these factors are individual and situational differences that may moderate the extent to which concordance is observed. DeHart and Pelham (2002) showed that participants from intact (as opposed to divorced) families evidenced a significant relation between implicit and explicit self-esteem; the relation was even stronger among those who completed the implicit measure using "gut impressions" rather than with extensive thought. In the domain of motivation, Thrash and Elliot (2002) found that individuals higher in self-determined (as opposed to controlled) motivation were more concordant in implicit and selfattributed need for achievement.

The present study tested whether the MAAS would predict concordance between implicit and explicit affect. Given the proposed self-regulatory nature of mindfulness, we hypothesized that higher MAAS scorers would show a closer relation between implicit and explicit affective states than those scoring lower on the MAAS. The focus on affect accords with the hypothesized role of mindfulness in subjective well-being, of which affect is a key feature (Diener et al., 1999). Although affect is typically assessed using self-report instruments, evidence indicates that it can also operate outside of awareness (Shevrin, 2000; Westen, 1998).

In the present study, the Implicit Association Test (IAT; Greenwald, McGhee, \& Schwartz, 1998) was used to assess automatic associations between self and affective states. ${ }^{3}$ The validity and reliability of the IAT as a measure of implicit processes has been demonstrated in a number of studies (e.g., Cunningham, Preacher, $\&$ Banaji, 2001). A primary assumption of the IAT is that strongly associated attribute-concept pairs are easier to classify together than are weakly associated or opposing pairs (Farnham, Greenwald, \& Banaji, 1998). Paralleling recent IAT tests of implicit self-esteem (e.g., Greenwald \& Farnham, 2000), in the present study, faster classifications (measured by response latency) of self and pleasant affect words together, rather than self and unpleasant affect words together, would provide evidence for automatic associations between self and predominantly pleasant hedonic tone. An explicit, self-report measure of affective state, along with the MAAS measure, was also collected.

\section{Method}

\section{Participants}

Ninety ( 31 male and 59 female) undergraduates, ranging in age from 18 to 26 ( $M=19.8$ years) participated in exchange for extra credit in psychology courses. Data from 7 additional participants were dropped from analysis because of high incorrect response rates (greater than $20 \%$ of trials) on the combined task blocks of the IAT (see below). Data from a further 5 participants were not used because of incorrect completion of, or outlying values on, one or more of the measures.

\section{Procedures}

\section{General Procedure}

Participants completed both self-report measures and the computerized IAT in a single session. Participants completed the study individually and, except when providing preliminary instructions, the experimenter was seated outside the experimental room. After the experimenter introduced the participant to the IAT program, the participant completed the IAT task by following instructions on the computer screen. The self-report and IAT tasks were counterbalanced, such that half the participants completed the self-report measures before the IAT task, and half completed them after the IAT.

Explicit measures. Embedded in a battery of self-report scales were the MAAS and a measure of current affective state adapted slightly from Diener and Emmons (1984). Following the instructions, "At the present time, to what degree are you experiencing the following emotions?" participants used a 7-point Likert scale from 1 (not at all) to 7 (extremely) to rate themselves on these adjectives: worried, happy, frustrated, pleased, angry, enjoying, unhappy, joyful, and depressed. To obtain an overall affect valence score, the average of the unpleasant affect item ratings was subtracted from the average of the pleasant items. The internal consistency (alpha) of both pleasant and unpleasant affect was .87 and .86, respectively, and for the MAAS it was .85 .

IAT task. This task (Greenwald et al., 1998) typically includes four word sets grouped into two concept pairs. To illustrate, the concept of self is represented by self-related words $(I, m e$, etc.) and, for contrast purposes, non-self-related words (they, them, etc.). The concept of emotion may be represented by a set of positive words (happy, joyful, etc.) and negative words (sad, afraid, etc.). This task has a target concept (self) and an attribute concept (emotion), and by combining the two can test the implicit positivity versus negativity of an individual's emotional state. In several blocks of practice trials, participants first categorize concept words into their respective groups by pressing a key on the left or right side of the computer keyboard, for example, "me" words on the left and "not me" words on the right; and in another trial block, positive words on the left, negative words on the right. As in priming tasks, participants are asked to respond quickly to avoid conscious or controlled cognitive processing of the stimulus associations. In the critical trial blocks, target and attribute concepts are combined, such that participants categorize self or positive words into one group and nonself or negative words into the other. The reverse pairings are made in a separate block of trials. If the individual has implicitly positive emotional associations with the self, words should be categorized faster in the self + positive/nonself + negative trial block than in the self + negative/nonself + positive trial block because the former concepts are more strongly associated at the implicit level. The IAT effect represents the difference in average response time between these two critical, combined concept trial blocks.

The procedure for the conduct of the IAT closely followed that used by Greenwald and colleagues (e.g., Greenwald et al., 1998; Greenwald \& Farnham, 2000). Because of space limitations, only the most pertinent details of the procedure will be described here. The IAT was administered on a PC using E-Prime software (Schneider, Eschman, \& Zuccolotto, 2002). The classification task used five stimulus words to refer to self ( $I$, $m e, m y$, mine, and the participant's name) and five to refer to nonself, or other (they, them, their, it, and other). These stimuli were very similar to those used by Farnham et al. (1998). To assess affect, we used the same adjectives as those on the Diener and Emmons (1984) self-report scale described above. The use of the same items on both explicit and implicit measures of affect ensured that differences in self-associations between the two measures could not be attributed to different affect constructs.

\footnotetext{
${ }^{3}$ The present study was interested in implicit-explicit concordance in state rather than trait affect, given that self-regulation through mindfulness could result in overriding of an implicit process (cf. Levesque \& Brown, 2002; Wilson et al., 2000) and therefore an absence of implicit-explicit concordance. Research using the IAT has shown that it can tap both dispositional and state phenomena (e.g., Gemar, Segal, Sagrati, \& Kennedy, 2001).
} 
The IAT task comprised seven blocks of speeded classification trials. In each block, participants were instructed to categorize, as quickly as possible, words that appeared in the center of the computer screen (classification stimuli) into one of two categories that remained at the top right and top left sides of the computer screen. Classification stimuli were placed into the right category with the right forefinger using the " 6 " key on the right side of the computer keyboard; words were placed into the left side category with the left forefinger using the "A" key of the keyboard. The seven trial blocks included practice blocks of 20 trials in classifying self (category label "me") versus nonself (category label "not me") stimulus words, pleasant affect ("pleasant") versus unpleasant affect ("unpleasant") words, and combined category classifications. The two critical data collection blocks (Blocks 4 and 7) had 40 trials of the combined category task. The order of these combined tasks was counterbalanced; half the participants were first asked to classify pleasant affect or self words versus unpleasant affect or nonself words ("pleasant or me" vs. "unpleasant or not me"); the other half were presented with the opposite combination first: pleasant affect or nonself words versus unpleasant affect or self words ("pleasant or not me" vs. "unpleasant or me"). In Block 7, each person completed the combined category task opposite to the one in Block 4. In each trial block, all stimulus items were drawn randomly until all words had been presented as stimuli before reuse.

Data reduction followed the procedures established by Greenwald and colleagues (e.g., Greenwald et al., 1998). Only the 40-trial combined tasks of Blocks 4 and 7 described above were used for analysis. In each of these blocks, responses to the first two trials were dropped, given their typically long response latencies. Also, latencies shorter than $300 \mathrm{~ms}$ or longer than 3,000 ms were recoded to $300 \mathrm{~ms}$ and 3,000 ms, respectively. Finally, a logarithm transformation was applied to the response latency data to normalize distributions.

\section{Results and Discussion}

Regarding first the implicit data, initial analyses examined the effects of gender and the two counterbalanced procedural variables-order of the two data collection blocks and order of selfreport-IAT task presentation-on the IAT effect. No significant effects were found. The samplewide IAT effect (mean latency for the self + unpleasant block - mean latency for the self + pleasant block) was $186.90 \mathrm{~ms}(S D=134.48)$. Participants responded significantly more quickly when associating self with pleasant affect rather than unpleasant affect words (Cohen's $d=1.64$ ), $t(89)=15.60, p<.0001$. On the explicit measure, participants described their current affect as predominantly pleasant rather than unpleasant $(M=1.48, S D=1.87)$. Across participants, however, there was a nonsignificant relation between implicit and explicit affect scores, $r(89)=.16, n s$. The average MAAS score in this study was $3.85(S D=0.68)$.

The primary purpose of this study was to examine whether the MAAS would moderate the (nonsignificant) relation between implicit and explicit affect. A multiple regression model was constructed in which explicit affect valence was regressed onto implicit affect valence, the MAAS, and the Implicit Affect $\times$ MAAS interaction term. We first centered the main effect predictors before computing the interaction term (see Aiken \& West, 1991). Preliminary analyses examining the effects of gender and implicitexplicit task order found that neither variable, alone or in interaction with other predictors, attained significance. Table 6 presents the results of the main regression analysis. Neither the implicit affect nor MAAS score main effects were significant. However, the interaction term was significant, $t(89)=2.16, p<.05$. As Figure 1 shows, more mindful individuals showed a stronger
Table 6

Multiple Regression Testing Moderation of Implicit

Affect-Explicit Affect Relation by Mindfulness (Study 3)

\begin{tabular}{llll}
\hline \multicolumn{1}{c}{ Predictor } & $B$ & $S E$ & $\beta$ \\
\hline Affect IAT effect & .13 & .21 & .07 \\
MAAS & .17 & .19 & .09 \\
Affect IAT $\times$ MAAS & .53 & .24 & $.24 *$ \\
\hline
\end{tabular}

Note. $\quad N=90$. IAT $=$ Implicit Association Test; MAAS $=$ Mindful Attention Awareness Scale.

$* p<.05$.

relation between implicit and explicit affect than those less dispositionally mindful. To verify this, analyses tested whether the slope of each regression line was significantly different from zero (see Aiken \& West, 1991). The slope for low mindfulness $(-.23,1$ standard deviation below the mean) was nonsignificant, $t(86)=$ $-0.74, n s$, whereas the slope for high mindfulness $(.49,1$ standard deviation above the mean) was significant, $t(86)=2.33, p<.05$.

In sum, using both implicit and explicit measures, participants in this study associated themselves with predominantly pleasant rather than unpleasant affect. However, the relation between implicit and explicit measures was small and nonsignificant (cf. Greenwald \& Farnham, 2000). The MAAS was shown to moderate the relation between implicit and explicit affect valence, such that individuals higher in mindfulness demonstrated a stronger relation between the two measures. The MAAS did not predict current affective state, but this is unsurprising, given that mindfulness is not theorized to predict emotional experience at a single point in time.

This study provides lab-based evidence for the construct validity of the MAAS and the self-regulatory capacity of mindfulness. The results showed that individuals scoring higher on the scale were more concordant with respect to their implicit and explicit affective experience, suggesting that more mindful individuals may be more attuned to their implicit emotions and reflect that awareness in their explicit self-descriptions. Although research is needed to more fully test this idea, these results accord with various theories of mindfulness that posit that the enhancement of this disposition, through practice or psychotherapy, for example, facilitates the uncovering of previously inaccessible emotional and other psychological realities (Wilber, 2000). Further, theories of self-regulation converge on the idea that attention to and awareness of one's current states facilitates psychological well-being. We turn our attention now to the role of MAAS-measured mindfulness in predicting both self-regulated behavior and well-being.

\section{STUDY 4. MINDFULNESS AS A PREDICTOR OF DAY-TO-DAY SELF-REGULATION AND WELL-BEING}

The results in Study 1 above show that the MAAS was correlated with several measures of self-regulation and a variety of indicators of psychological well-being. These correlations are provocative, but as J. E. Schwartz and Stone (1998) pointed out, biases can be introduced by the cognitive processes involved in summarizing the kind of retrospective information requested on one-occasion self-reports. As such, it is important to assess 


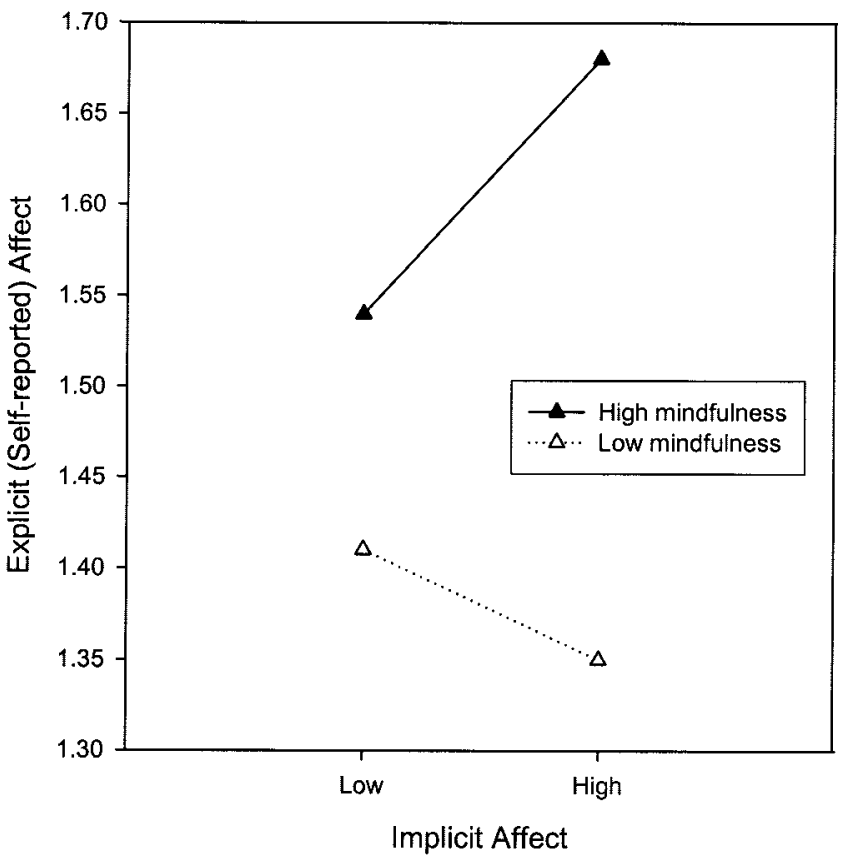

Figure 1. Moderation effect of Mindful Attention Awareness Scale mindfulness on the relation between implicit and explicit affect valence. High and low values are 1 standard deviation above and below the mean, respectively.

whether a self-report measure taps what is occurring in individuals' regular day-to-day lives. In this study, measures of selfregulated behavior (autonomy) and emotional state were collected multiple times a day over a period of weeks through experience sampling. This approach allowed for the measurement of affect and behavior on a quasi-random basis to obtain a reasonably representative picture of these outcomes in daily life. We hypothesized that the MAAS would predict more autonomous activity and higher levels of emotional well-being over time.

Traits are often assumed to be temporally consistent characteristics, as classically defined. But we theorize that mindfulness is inherently a state, and thus is also variable within persons, apart from the general tendency to be mindful. Recent research has shown substantial variability across time in several phenomena that clearly qualify as traits, including Big Five dispositions (Sheldon, Ryan, Rawsthorne, \& Ilardi, 1997), interpersonal behavior (Brown \& Moskowitz, 1998), and attachment styles (LaGuardia, Ryan, Couchman, \& Deci, 2000), among others. Further, both emotional states and autonomous behavior are known to vary over time both within and between persons (Reis, Sheldon, Gable, Roscoe, \& Ryan, 2000; Sheldon, Ryan, \& Reis, 1996). Thus, a second major purpose of this study was to assess the degree of within-person variability in mindfulness and relate it to withinperson variability in autonomy and emotional well-being.

As Reis et al. (2000) discussed, trait (between-person) and state (within-person) effects are both conceptually and statistically independent. A trait effect relates stable individual differences to average levels of an outcome across days. State effects identify systematic fluctuations above and below (that is, controlling for) each person's average level on that variable. In line with hypotheses regarding the trait form of the MAAS, we hypothesized that state or momentary mindfulness would be related to autonomous action and emotional well-being measured at the same point in time. We further predicted that state mindfulness would be more strongly related to momentary outcomes than the trait measure given its temporal proximity to ongoing events and experiences. However, because trait is defined as a propensity to act in a particular way, we can expect a person to have a tendency to behave that way in his or her typical environment. As such, some correspondence between the trait MAAS measure and average state ratings of mindfulness was expected.

In sum, we hypothesized that trait mindfulness would predict both state mindfulness and day-to-day autonomous action and emotional well-being. It was predicted that state mindfulness would be related to autonomy and emotional state measured at the same point in time. In general, finding significant effects at both trait and state levels would support the position that mindfulness plays a broad and important role in self-regulation and emotional experience.

\section{Method}

\section{Participants}

\section{Sample 1}

Participants (Sample F, Table 1) were employed adults drawn from the Rochester, New York area. From approximately 200 phone calls received in response to local newspaper and poster advertisements, 83 participants were enrolled after screening for four criteria: (a) They were at least 18 years old; (b) to help ensure homogeneity across participants in diurnal activity patterns, participants were currently working at least $30 \mathrm{hr}$ per week in the daytime; (c) they were the primary spender of their household's money; and (d) they spent money at least three times per week. The latter two criteria were set for purposes of another study (Brown, Kasser, Ryan, \& Konow, 2002). Of the 83 individuals enrolled, data from 9 were excluded -7 because of failure to complete the experience-sampling phase of the study, 1 because of extraordinarily long pager signal response times, and 1 because of a large number of sampling forms completed incorrectly. Thus, 74 participants (55\% female) successfully completed the study, ranging in age from 18 to 62 years $(M=37.6)$. Each received both a personalized research report and $\$ 50$ for completing the study.

\section{Sample 2}

Students from an introductory psychology course at a small Northeastern U.S. university participated for extra credit. Of 100 who began the study, 1 did not comply with questionnaire instructions, and 7 did not complete the experience sampling portion, leaving 92 "completers" (74\% female) who ranged in age from 18 to 21 years $(M=19.5)$.

\section{Procedure}

Participants in both samples completed demographic and all psychological measures during an experience-sampling training session. Trainings were conducted on Mondays and Tuesdays, and all participants began experience-sampled recordings on the immediately following Wednesday. Keeping the starting day constant facilitates the analysis of day-of-week effects. Participants were given a pager user's guide and sampling form instructions, along with contact information if questions arose.

Participants recorded their experiences for 21 (Sample 1) and 14 (Sample 2) consecutive days using identical forms bound into a small pad. Each 
form took approximately $1 \mathrm{~min}$ to complete. On each form, participants also recorded the time lag from pager signal to record completion. Pager signals were sent 3 times per day on a quasi-random schedule: one between 9 a.m. and 1 p.m.; one between 1 p.m. and 5 p.m.; and the last between 5 p.m. and 9 p.m. On weekends, the first signal was sent between 10 a.m. and 1 p.m. Within these time frames, the signal was sent randomly, with the constraint that signals not be sent within $2 \mathrm{hr}$ of each other (cf. Shiffman, 2000). Signal schedules were generated by Random 2.1 software (Wild, 1999).

Forms were returned in stamped, self-addressed envelopes each day subsequent to recording. Throughout the study, a detailed log of returned forms was kept to check compliance. Deviations from protocol prompted an immediate phone call or e-mail to the participant to clarify the study procedures and rectify any difficulties. All participants received two "booster" contacts (cf. Litt, Cooney, \& Morse, 1998) during the sampling period to encourage adherence. At the end of the sampling period, participants returned to the lab to complete closing questionnaires and for debriefing.

\section{Measures}

\section{Trait Mindfulness}

The MAAS was completed before the experience-sampling phase of the study. The alphas were .86 and .87 for Samples 1 and 2, respectively.

\section{Baseline Affect}

To control for baseline emotional state, the 9-item Diener and Emmons (1984) scale of affect valence (pleasantness-unpleasantness) was completed before experience sampling. The emotion adjectives were happy, worried/anxious, frustrated, pleased, angry/hostile, enjoyment/fun, unhappy, depressed/blue, and joyful. Using a 7-point scale from 1 (not at all) to 7 (extremely), participants indicated their emotional state "over the past week." The alphas for pleasant and unpleasant affect were .86 and .78 , respectively, for Sample 1 and .90 and .85 , respectively, for Sample 2.

\section{State Mindfulness (Sample 2 Only)}

After answering the question (in one or two words), "What were you MAINLY doing at the time of the signal?" the sampling form asked, "To what degree were you having these experiences?" Following this were five items drawn from the MAAS (and slightly rephrased) to assess state mindfulness. These items $(3,8,10,13$, and 14 ; see Table 2$)$ had sufficient generality to be applicable to a multitude of situations. Each was rated on a 7-point scale anchored at 0 (not at all), 3 (somewhat), and 6 (very much). A state mindfulness score was derived by first reverse scoring and then averaging responses; higher scores reflected more mindful states. When collapsed across time, the internal consistency (alpha) of this measure was 92 .

\section{State Relative Autonomy}

An adaptation of the Perceived Locus of Causality scale (Ryan \& Connell, 1989) was used to measure the relative controlled versus autonomous nature of the activity the participant was engaged in at the time of the pager signal. This measure has been used extensively to examine self-regulated activity in diary studies (Reis et al., 2000; Sheldon et al., 1996). After being asked to briefly describe the activity engaged in, the sampling form asked, "Why were you engaged in this activity?". Five statements followed: (a) "Because other(s) wanted me to, or pressured me to"; (b) "To help me look good to other(s)"; (c) "To help me feel better about myself"; (d) "Because I truly valued it"; and (e) "Because it was fun or interesting to do." Each statement was rated on a 7-point scale with anchors at 0 (not at all), 3 (somewhat), and 6 (completely). A relative autonomy index (RAI) was formed by weighting each statement and then averaging the weighted statement values on each form (see Sheldon et al., 1997). Scores on the RAI could range from -18 to +18 , with higher scores reflecting greater autonomy.

\section{Emotional State}

The same list of nine emotion adjectives on the baseline affect scale (Diener \& Emmons, 1984) was used to assess momentary affect valence. Participants responded to the question, "How did you feel emotionally during this activity?" using a 7-point scale anchored at 0 (not at all), 3 (somewhat), and 6 (extremely). Mean scores for both pleasant and unpleasant affect were computed for each momentary assessment. When collapsed across time, the reliability of the scales was .94 and .94 , respectively, for Sample 1, and .93 and .92 for Sample 2 .

\section{Results}

In both samples, compliance with procedures and timely completion of forms was good. In Sample 1, 4,260 (91.4\%) of 4,662 possible forms (74 participants $\times 63$ signals) were returned. The number of minutes from signal to form completion was $M=11.04$ $(S D=26.57)$. Most $(83.8 \%)$ were completed within $15 \mathrm{~min}$ of the pager signal. A small percentage $(3.3 \%)$ were completed after 60 min; data from these forms were excluded from analyses to avoid retrospective biases. This left 4,118 data points for analysis ( $M$ per participant $=56$, range $=30-63)$. In Sample 2, 3,662 $(94.8 \%)$ of 3,864 possible forms ( 92 participants $\times 42$ signals) were completed and returned. The number of minutes from signal to form completion was $M=8.12(S D=24.00)$. Again, most forms $(89.3 \%)$ were completed within $15 \mathrm{~min}$. The $3 \%$ of forms completed after $60 \mathrm{~min}$ were excluded, leaving 3,559 data points in this sample ( $M$ number per participant $=39$, range $=24-42$ forms).

Using aggregated sampling data, the MAAS was correlated with day-to-day autonomy (Sample 1: $r=.27, p<.05$; Sample 2: $r=$ $.28, p<.01)$. MAAS scores were unrelated to day-to-day pleasant affect (Sample 1: $r=.08, n s$; Sample 2: $r=.13, n s$ ), but were strongly and inversely related to unpleasant affect experiences (Sample 1: $r=-.49, p<.0001$; Sample 2: $r=-.33, p<.01$ ). As in other diary research (e.g., Brown \& Moskowitz, 1997), day-to-day pleasant and unpleasant affect scores were unrelated (Sample 1: $r=.02, n s$; Sample 2: $r=.12, n s$ ).

\section{Multilevel Models}

A multilevel random coefficient modeling (MRCM) approach was used (e.g., Bryk \& Raudenbush, 1992; Kreft \& deLeeuw, 1998). The MRCM approach is well suited to hierarchically nested data structures in which a lower level unit of analysis (Level 1; e.g., momentary reports) is nested within a higher level of analysis (Level 2; e.g., persons). Among other advantages (see Reis et al., 2000; J. E. Schwartz \& Stone, 1998), such models are able to incorporate tests of the three primary characteristics that commonly appear in time-serial data: linear trend over time, regular cyclicity over intervals of time, and serial autocorrelation (West \& Hepworth, 1991). The MIXED procedure in SAS was used to estimate all models (SAS Institute, 1992, 1997).

We first examined the relations between person-level trait mindfulness and momentary-level autonomy and pleasant and unpleasant affect. Next, we examined the relation between person-level 
and momentary-level mindfulness in order to assess the construct validity of the state measure. The reliability of the state measure was also assessed. We then tested whether momentary variation in state mindfulness was related to fluctuations in autonomy and affective state at the same point in time. In these analyses, the effect of trait mindfulness was also tested so that the average within-person association between state mindfulness and the dependent variables could be assessed in conjunction with betweenperson differences in mindfulness. Several demographic and time series variables were also included in the models: gender, age (Sample 1 only), day of study and time of day (both testing for linear trend), a cosine term (to model weekly cyclicity), ${ }^{4}$ and time of momentary report completion (to test for first-order autocorrelation in each of the dependent variables). ${ }^{5}$ To enhance interpretability of the model intercept parameters (Bryk \& Raudenbush, 1992; J. E. Schwartz \& Stone, 1998), the predictor variables were pretreated: between-person (trait) mindfulness was centered around the sample mean, whereas within-person (state) mindfulness was person centered. Other variables that did not include a meaningful zero value in the original scaling (gender, age, day of study, and time of day) were rescaled to include zero.

Unconditional means models established that there was significant between- and within-subjects variation in each of the experience-sampled measures in both samples (all $p \mathrm{~s}<.0001$ ). The top of Table 7 displays the Sample 1 results of the multilevel analysis with all predictors included simultaneously in the equations. Most pertinently, MAAS-assessed mindfulness predicted higher levels of day-to-day autonomy and lower levels of unpleasant affect $(t=2.79, p<.01$, and $t=-5.57, p<.0001$,

Table 7

Predictions of Day-to-Day Autonomy and Affect From Mindful Attention Awareness Scale-Measured Mindfulness, Demographics, and Time Serial Variables in Both Adult Community Members (Sample 1) and College Students (Sample 2) (Study 4)

\begin{tabular}{|c|c|c|c|}
\hline \multirow[b]{2}{*}{ Predictor } & \multicolumn{3}{|c|}{ Estimate } \\
\hline & Autonomy & Pleasant affect & Unpleasant affect \\
\hline \multicolumn{4}{|c|}{ Sample $1(N=74)$} \\
\hline Gender & -0.23 & 0.25 & $0.33^{* *} *$ \\
\hline Age & $-0.09 * *$ & -0.02 & 0.00 \\
\hline Time of day & $1.21 * * * *$ & $0.19 * * * *$ & $-0.07 * * * *$ \\
\hline Day of study & $0.06^{* * * *}$ & 0.00 & 0.00 \\
\hline Weekly cyclicity & $-0.59 * * *$ & $-0.24 * * * *$ & $0.06^{* * *}$ \\
\hline Autocorrelation & $0.99 * * * *$ & 0.59 & $0.95 * * * *$ \\
\hline Trait mindfulness & $1.63 * *$ & 0.14 & $-0.47 * * * *$ \\
\hline
\end{tabular}

Sample $2(N=92)$

\begin{tabular}{lccc} 
Gender & -0.97 & -0.09 & 0.01 \\
Age & - & - & - \\
Time of day & $0.67 * * * *$ & $0.26 * * * *$ & -0.01 \\
Day of study & -0.03 & $-0.02 * *$ & $0.01 *$ \\
Weekly cyclicity & $-0.69 * * * *$ & $-0.22 * * * *$ & $0.14 * * * *$ \\
Autocorrelation & 0.04 & 0.62 & 0.14 \\
Trait mindfulness & $1.12 * *$ & 0.16 & $-0.26 * *$ \\
\hline
\end{tabular}

Note. Values are unstandardized parameter estimates. $* p<.05 . \quad * * p<.01 . \quad * * * p<.001 . \quad * * * * p<.0001$. respectively). The MAAS did not predict experiences of pleasant affect, however. Comparison of the covariance parameter estimates between the autonomy and unpleasant models and parallel models including only the demographic and time series predictors (see Singer, 1998) showed that the MAAS uniquely accounted for $10 \%$ of the explainable between-subjects variation in autonomy and $31 \%$ of the between-subjects variation in unpleasant affect.

The effect of dispositional mindfulness on day-to-day outcomes was also tested in Sample 2 while controlling for demographic and time series variables (see the bottom of Table 7). MAAS-measured mindfulness again predicted more autonomous activity $(t=2.63$, $p<.01)$ and less unpleasant affect day to day $(t=-3.27, p<$ $.01)$. It did not predict pleasant affective state. The MAAS explained $7 \%$ of the between-subjects variation in autonomy and $10 \%$ of the between-subjects variation in unpleasant affect. When the data were analyzed using experience-sampled affect frequency scores, the results in both samples were very similar to those presented here.

To explore the role of state mindfulness in predicting autonomy and affect, it was first important to demonstrate its reliability. As noted (see the Method section, above), the measure showed high internal consistency ( $\alpha=.92$ ). Further evidence of reliability was obtained by calculating an intraclass correlation $\rho$, which indicates the portion of total variance that occurs between persons (Singer, 1998); that is, to what extent is the variation in state mindfulness over time attributable to between-person differences? Using an unconditional means model with state MAAS as the outcome, $\rho=$ .29 , indicating that $29 \%$ of the variation in state mindfulness was attributed to individual differences, and $71 \%$ was attributable to within-person variability.

To assess the validity of the state measure, we used the trait measure as a yardstick, given the evidence for its reliability and validity, and assessed the strength of the relation between the trait and state measures. This was done in two ways. First, a multilevel model was constructed with state mindfulness regressed onto the trait scale. A strong predictive relation was found $(B=.46$, $t=4.57, p<.0001)$. This indicates that individuals scoring higher in trait mindfulness were more likely to show higher levels of momentary mindfulness over time. The strength of the relation

\footnotetext{
${ }^{4}$ The fit of a sine function was also examined, but across analyses, a cosine function consistently provided a better fit. We tested for septurnal, or 7-day weekly, cyclicity because this is the most common interval over which cyclical effects have been reported in both pleasant and unpleasant affect (e.g., Brown, 1998; Larsen \& Kasimatis, 1991) and autonomy (Reis et al., 2000). Cyclicity is most commonly tested with either a dummy variable approach or the trigonometric approach used here (Bowerman \& O'Connell, 1993). Because we were not interested in specific day-of-week effects, we chose the latter approach, which allows for fewer terms in model equations.

${ }^{5}$ A continuous time variable was created, in which the day and time that each record form was completed was used to create a continuous time variable that started at Day 1 , Record 1 , and ran linearly upward to day $n$, record $n$. For each sampling record, the number of minutes after the pager signal that the form was completed was subtracted from the actual time of record completion to derive the actual time referred to by each record's data. Incorporation of time into SAS PROC MIXED to test for autocorrelation was discussed by J. E. Schwartz and Stone (1998).
} 
between trait and state scores was also measured as the amount of between-person variance in mean state scores accounted for by trait score. The covariance between these two measures was .19; this translates into a correlation of .44 . These results suggest that the subset of items from the MAAS used to measure state mindfulness adequately capture the construct.

Table 8 shows results of analyses using both trait and state mindfulness to predict autonomy and emotions while controlling for gender and the time series variables. To test these relations, a term representing the effect of state mindfulness was added to the preexisting model. The state measure predicted autonomy, pleasant affect, and unpleasant affect: When individuals were more attentive to the activities they were engaged in, they were also more likely to experience those activities as autonomous $(t=10.71, p<.0001)$ and to evidence higher levels of pleasant emotion and lower levels of unpleasant emotion $(t=7.93$ and $t=$ -8.72 , respectively, both $\mathrm{ps}<.0001)$. A comparison of the covariance parameter estimates between these models and models including only the demographic, time series, and trait MAAS predictors (presented earlier) showed that state mindfulness uniquely accounted for $16 \%$ of the explainable between-subjects variation in autonomy, $14 \%$ of the variation in pleasant affect, and $16 \%$ of the between-subjects variation in unpleasant affect. Notably, the effect of trait MAAS in predicting more autonomous activity and less unpleasant affect remained significant in these models ( $t=2.56, p<.01$, and $t=-3.39, p<.001$, respectively). Similar results were found using affect frequency scores. The interaction between trait and state mindfulness was also tested in these models. This term was marginally significant in the prediction of pleasant affect $(p<.10)$ and nonsignificant in the prediction of autonomy and unpleasant affect. Thus, the covariation between state mindfulness and both autonomous activity and affective experience was not limited to those with higher trait mindfulness. Finally, analyses were conducted in which baseline affect scores were controlled for in the prediction of the three experiencesampled variables. In eight of the nine models presented here (see Tables 7 and 8), the mindfulness predictors (trait and state) remained significant (all $p s<.05$ ). In the prediction of autonomy in Sample 1 , trait mindfulness became marginally significant $(p<$ $.06)$.

Table 8

Predictions of Day-to-Day Autonomy and Affect From Trait and State Mindfulness, Gender, and Time Serial Variables (Sample 2, Study 4, $N=92$ )

\begin{tabular}{lccc}
\hline & \multicolumn{3}{c}{ Estimate } \\
\cline { 2 - 4 } \multicolumn{1}{c}{ Predictor } & Autonomy & Pleasant affect & Unpleasant affect \\
\hline Gender & -0.98 & -0.06 & -0.03 \\
Time of day & $0.53^{* * * *}$ & $0.23^{* * * *}$ & 0.02 \\
Day of study & -0.03 & $-0.02^{* *}$ & $0.01^{*}$ \\
Weekly cyclicity & $-0.51^{* * *}$ & $-0.19^{* * * *}$ & $0.11^{* * * *}$ \\
Autocorrelation & 0.02 & $0.71^{* *}$ & 0.13 \\
Trait mindfulness & $1.08^{* * *}$ & 0.10 & $-0.26^{* *}$ \\
State mindfulness & $1.59^{* * * *}$ & $0.25^{* * * *}$ & $-0.22^{* * * *}$ \\
\hline
\end{tabular}

Note. Values are unstandardized parameter estimates.

$* p<.05$. ** $p<.01$. *** $p<.001$. **** $p<.0001$.

\section{Discussion}

This study assessed the prediction of day-to-day self-regulatory and emotional well-being outcomes from mindfulness, operationalized in trait terms using the MAAS and in dynamic, state terms using a brief adaptation of the MAAS. Consistent with hypotheses, trait mindfulness predicted more autonomous activity in day-today life and lower levels of unpleasant affect, measured both in intensity and frequency. Trait MAAS did not predict experiencesampled pleasant affect. However, state mindfulness was associated with positive experiences across the three outcomes: higher levels of autonomy, more intense and frequent pleasant affect, and less intense and less frequent unpleasant affect. The effects of trait and state mindfulness were independent; that is, having the disposition to be mindful had salutary effects on self-regulated activity and emotional well-being, but so did momentary experiences of mindfulness, independent of the disposition. As predicted, the effects of state mindfulness were stronger than those for the trait measure, perhaps because of the temporal proximity of the measure of state mindfulness to the outcomes studied. Although the trait and state effects of mindfulness on momentary experience were independent, the two measures were related: Being momentarily mindful was more likely among those who had the disposition, lending further support to the validity of the MAAS.

According to SDT, from which the measure of autonomy was derived, autonomy reflects behavior that is fully endorsed by the self. The present results indicate that when acting mindfully, individuals are acting in ways that are concordant with values and interests. It is also likely that feelings of choice as well as feelings of enjoyment increase mindful attention to one's actions (Langer, 1989). The interconnection between mindfulness, volitional regulation of behavior, and hedonic experience suggests interesting avenues for further research.

Both the correlational results presented above (Study 1) and the present multilevel modeling results showed that the MAAS bore weaker relations to pleasant affect than to unpleasant affect, whereas state mindfulness predicted both in this study. These results may indicate that a dispositionally more mindful person could be expected to show a generally mild emotional demeanor. Such a person would not be characterized as happy in the sense in which it is frequently defined-as experiencing a preponderance of positive and paucity of negative emotional states. However, spiritual traditions that discuss the effects of mindfulness typically place greater emphasis on equanimity and peace of mind than on happiness per se; as Baumeister (1991) noted, "Spirituality seeks not just an emotional high but a state of peace, tranquillity, and understanding" (p. 196). Indeed, mindfulness is thought to create a witnessing or observant stance toward ongoing emotional and other psychological experiences, the result of which appears, from the present results, to promote a balanced or even-keeled emotional life. These trait results did not fully parallel those found with the state measure, which indicated that momentary presence of mind is associated with more pleasant affect and less unpleasant affect - the very picture of a happy person in that moment. Although the trait and state results on affect differed, they are not necessarily incompatible, and future research exploring the temporal course of emotional experiences among those varying in dispositional mindfulness may shed more light on this issue. 


\section{STUDY 5. EFFECTS OF MINDFULNESS ON WELL-BEING IN A CLINICAL CONTEXT}

The research presented thus far offers support for the role of mindfulness in fostering well-being and self-regulated behavior. Thus, the cultivation or enhancement of mindfulness can be recommended. Indeed, past research has shown that training in mindfulness facilitates well-being outcomes in a variety of populations. Kabat-Zinn and colleagues have shown that a standardized 8-week mindfulness-based stress reduction (MBSR) program can be effective in reducing psychological symptoms among anxiety (Kabat-Zinn et al., 1992) and pain (Kabat-Zinn, Lipworth, \& Burney, 1985) patients, for example. Research conducted by others, much of it modeled after or adapted from the MBSR program, has also demonstrated positive outcomes in medical (e.g., Reibel, Greeson, Brainard, \& Rosenzweig, 2001; Speca, Carlson, Goodey, \& Angen, 2000), psychiatric (Linehan, Cochran, \& Kehrer, 2001; Teasdale et al., 2000), community adult (Williams, Kolar, Reger, \& Pearson, 2001), and student (Astin, 1997; Shapiro et al., 1998) samples.

Although these findings are important, past research has not determined whether it is mindfulness itself that enhances psychological well-being, because measures of mindfulness have not been available. Research has tested only the effectiveness of the training programs, and compliance with them, in facilitating well-being. The purpose of this clinical intervention study was to determine whether changes on the MAAS related to changes in adjustment and well-being.

Building on the work of Speca et al. (2000) and Carlson, Ursuliak, Goodey, Angen, and Speca (2001), this study was conducted with early-stage breast and prostate cancer patients. Interventions designed to enhance well-being among cancer patients are supported by research showing that moderate to high levels of stress are commonly experienced by individuals attempting to cope with the disease and its consequences (e.g., Sellick \& Crooks, 1999; Sheard \& Maguire, 1999). In this study, patients were enrolled in an 8-week MBSR program. Measures of mood disturbance, stress, and the MAAS were administered before and after the program. We hypothesized that changes in MAAS-measured mindfulness over the training period would predict changes in emotional disturbance and stress. Also, to test the association between mindfulness and both mood and stress at single points in time, relations between MAAS and well-being scores were examined both pre- and postintervention. Our interest here was applied - that is, whether the MAAS could be validly and productively used to predict well-being in a clinical context.

\section{Method}

\section{Participants}

Patients were eligible if they met the following inclusion criteria: (a) age 18 or older; (b) a diagnosis of Stage 0 , I, or II breast or early-stage (localized) prostate cancer at any time in the past; and (c) a minimum of 3 months since cancer surgery (e.g., mastectomy, prostatectomy). Breast and prostate cancers have similarly positive prognoses in the early stages, and offer similar, though often differently expressed, degrees of physical and psychological challenge (DeFlorio \& Masie, 1995; Keller \& Henrich, 1999). Breast and prostate cancers are also the most currently prevalent carcinomas for women and men, respectively (National Cancer Institute of Canada, 2001). Several exclusion criteria were also set: (a) treatment with chemotherapy, radiation therapy, or hormone therapy within the past 3 months; (b) a concurrent Diagnostic and Statistical Manual of Mental Disorders (4th ed.; American Psychiatric Association, 1994) Axis I diagnosis; (c) current use of psychotropic medications (e.g., antidepressants, anxiolytics); (d) a concurrent autoimmune disorder; and (e) past participation in an MBSR group.

A total of 58 breast and prostate cancer patients was accrued through clinical staff referrals and advertisements in the oncology clinics of a major Canadian cancer center. Seven individuals did not complete the intervention because of scheduling or work difficulties. Additionally, 1 person did not complete the Time 1 measures, and 9 did not complete Time 2 measures. Thus, data from 41 individuals were used in the present analyses. Comparisons of the 17 patients with incomplete data with the rest of the sample on all demographic, medical, and psychological variables collected at baseline (preintervention) showed that completers were more likely to be married or cohabitating rather than single, divorced, or widowed, $\chi^{2}(1$, $N=58)=9.20, p<.005$. No other differences on demographic or medical variables were found. Noncompleters had higher scores on several of the baseline POMS scales: Depression/Dejection, $t(56)=3.65, p<$ .001 ; Anger/Hostility, $t(56)=2.88, p<.01$; and Confusion, $t(56)=2.17$, $p<.05$. Such differences are consistent with other research; cancer patients experiencing emotional and cognitive disturbance appear less likely to comply with treatment regimens or to participate in research (Spiegel, 1996). However, the present results must be interpreted in light of potential biases due to sample attrition, given differences in marital status and three of the POMS scale scores. No baseline differences on the Symptoms of Stress Inventory (SOSI), or the MAAS were found.

Final sample characteristics are presented in Table 9. Most patients $(n=$ 32 ) were age 50 or older (range $=37-76$ years), and all were working at least to some extent outside the home. Of the 41 patients, 32 had breast cancer (all women) and 9 had prostate cancer. Fourteen patients had Stage I cancers and 26 had Stage II cancers. The average time since diagnosis was 2 years.

Table 9

Selected Patient Characteristics (Study 5)

\begin{tabular}{|c|c|c|c|c|}
\hline Variable & $M$ & $S D$ & $\%$ & Range \\
\hline Gender (\% female) & & & 78.0 & \\
\hline Age (years) & 55.31 & 10.02 & & $36.92,75.89$ \\
\hline Married & & & 85.4 & \\
\hline Education (years) & 14.63 & 2.89 & & $10.00,24.00$ \\
\hline Work hours/week & 27.08 & 11.55 & & $3.00,51.00$ \\
\hline \multicolumn{5}{|l|}{ Cancer stage } \\
\hline I & & & 35.0 & \\
\hline II & & & 65.0 & \\
\hline $\begin{array}{l}\text { Time since diagnosis } \\
\text { (years) }\end{array}$ & 2.05 & 2.24 & & $0.39,10.00$ \\
\hline \multicolumn{5}{|l|}{$\begin{array}{l}\text { Quality of life-physical } \\
\text { (EORTC QLQ) }\end{array}$} \\
\hline Functioning & 184.88 & 19.89 & & $120.00,200.00$ \\
\hline \multicolumn{5}{|l|}{ Symptoms } \\
\hline Fatigue & 34.42 & 21.20 & & $0,100.00$ \\
\hline Pain & 23.33 & 24.38 & & $0,100.00$ \\
\hline Mindfulness (MAAS) & 4.27 & 0.64 & & $2.60,5.36$ \\
\hline Mood disturbance (POMS) & 13.88 & 27.92 & & $-30.00,85.00$ \\
\hline Stress symptoms (SOSI) & 82.17 & 48.22 & & $17.00,182.00$ \\
\hline
\end{tabular}

Note. EORTC QLQ = European Organization for Research and Treatment of Cancer Quality of Life Questionnaire; MAAS = Mindful Attention Awareness Scale; POMS = Profile of Mood States; SOSI = Symptoms of Stress Inventory. 


\section{Procedure and Measures}

Baseline (Time 1) assessments on all measures were completed 1 week prior to the start of the intervention. Disease data were later verified through hospital charts. Within 2 weeks following the 8-week intervention, patients again completed the psychological measures (Time 2). At Time 1, demographic and medical information collected included age, gender, marital status, number of work hours per week, education level, and time since diagnosis. Stage of cancer was unknown to many patients, so this information was abstracted from hospital records by a trained research nurse naive to the purpose of this study.

Physical functioning and symptoms were assessed using the European Organization for Research and Treatment of Cancer Quality of Life Questionnaire (EORTC QLQ; Aaronson et al., 1993). The Physical Functioning subscale is composed of five yes-no questions concerning everyday physical capabilities (e.g., "Do you have any trouble doing strenuous exercises, like carrying a heavy shopping bag or a suitcase?"). The Kuder-Richardson coefficient internal consistency of the scale was $.61 .^{6}$ The EORTC QLQ assesses physical symptoms using 3 scales, Fatigue ( 3 items), Nausea (2 items), and Pain (2 items), along with 6 single items assessing dyspnea, sleep disturbance, appetite loss, constipation, diarrhea, and financial impact of symptoms. All items are rated on a 4-point scale from 1 (not at all) to 4 (very mисh). All but the Fatigue and Pain items showed very low rates of endorsement, so these items will not be further considered. In this sample, the internal consistencies of the Fatigue and Pain scales were .84 and .89 , respectively.

The 65-item POMS (McNair et al., 1971) is widely used in psychooncology and health research, and norms are available for cancer patients (e.g., Cassileth, Lusk, Brown, \& Cross, 1985). Using a 5-point scale, respondents indicate to what extent the items applied to them in the past week. The scale yields a total mood disturbance score and six subscale scores: Tension/Anxiety, Depression/Dejection, Anger/Hostility, Vigor, Fatigue, and Confusion. The POMS has demonstrated sensitivity to mood changes within patient groups (Gotay \& Stern, 1995). In this sample, subscale alphas ranged from .81 to .94 .

The SOSI (Leckie \& Thompson, 1979) measures physical, psychological, and behavioral responses to stressful situations over a designated time frame (the past week in this study). The 95 items are rated on a 5-point scale from 1 (never) to 5 (very frequently). A total stress symptoms score is produced, along with 10 subscale scores: Peripheral Manifestations (e.g., hot or cold spells, flushing of face), Cardiopulmonary, Arousal, Upper Respiratory, Central Nervous System, Gastrointestinal, Muscle Tension, Habitual Patterns, Depression, Anxiety, Emotional Irritability, and Cognitive Disorientation. In this sample, subscale alphas ranged from .63 to .88.

The MAAS was administered pre- and postintervention. The sample alpha was .83 .

\section{Intervention}

A detailed description of the mindfulness training program used in this study has been provided by Speca et al. (2000). The program was modeled on the work of Kabat-Zinn and colleagues (e.g., Kabat-Zinn, 1990) and was adapted and standardized to a cancer treatment context. The intervention consisted of 8 weekly 90-min group sessions held at the hospital and one 3-hr retreat that took place between Weeks 6 and 7. Didactic, inductive, and experiential modes of learning were used. Training consisted of three primary components: (a) theoretical material related to relaxation, mindfulness, and body-mind connections; (b) experiential practice of mindfulness both during group meetings and at home on a daily basis; and (c) group process focused on problem solving related to impediments to effective practice, day-to-day applications of mindfulness, and supportive interaction. In addition, a booklet was provided containing information pertinent to each week's instruction, as well as bibliographic resources and audiotapes with relaxation and guided mindfulness exercises.
A core principle of the program was that intentional management of attention and awareness (i.e., mindfulness) affords multiple points of application in the recursive process of adapting to illness. A variety of specific mindfulness techniques were taught (e.g., attention to breathing, awareness of bodily sensations). The clinical value of this approach was supported by previous research (Speca et al., 2000), which found individual patient differences in the preference for and success with different techniques. The program instructors, two clinical psychologists and one clinical social worker, had been offering MBSR programs since 1996.

\section{Results}

As Table 9 shows, EORTC QLQ scores at the study outset indicated that, on average, participants had a high level of daily functioning and low to moderate levels of fatigue and pain. Scores on the MAAS were somewhat higher than those observed in the other adult samples reported in this article. Average scores on the SOSI and POMS were comparable to that seen in other cancer patient samples, including those with early stage breast and prostate cancers (e.g., Carlson, Ottenbreit, St. Pierre, \& Bultz, 2001; Speca et al., 2000). Most participants were well past the early postdiagnostic phase, when emotional disturbance is generally more pronounced (e.g., Sellick \& Crooks, 1999).

Paired $t$ tests were conducted on Time 1 to Time 2 changes in MAAS, POMS, and SOSI scores. SOSI scores showed a significant drop over the intervention period, $t(40)=3.27, p<.01$. Neither samplewide MAAS nor POMS scores showed a significant change. Notable for both the mood and stress variables was the high standard deviation and range of the scores (see Table 9). Similar degrees of variability were observed in the Time 2 scores and the scores representing change over time. Examination of change in outcomes showed that POMS scores increased up to $50 \%$ and dropped as much as $30 \%$ across participants. SOSI scores increased up to $15 \%$ and decreased as much as $30 \%$. Thus, in both variables there was substantial variability to explain.

In testing the relations between mindfulness and the outcomes, we controlled for the effects of demographic, medical, and physical health variables. Past research has shown that variables such as time since diagnosis (Velikova et al., 2001) and symptoms related to cancer (Nordin, Berglund, Glimelius, \& Sjoden, 2001) can impact psychological state. Accordingly, multiple regression analyses were performed using data from Time 1, Time 2, and the change across time, in which the two outcome variables-total mood disturbance and total stress-were regressed on MAAS scores while controlling for any demographic, medical, or health variables that showed significant relations to these outcomes in preliminary analyses.

None of the demographic variables except gender were significantly related to the psychological outcomes. Specifically, women showed higher stress scores than men at Time $1, t(39)=2.16, p<$ .05. However, in a preliminary regression analysis with other predictors in the equation, gender did not significantly predict Time 1 stress. Thus, to simplify the presentation of the results, this variable was not further considered.

Table 10 shows the intercorrelations of the medical, physical health, MAAS, and outcome variables at Time 1 and Time 2. Stage

\footnotetext{
${ }^{6}$ In this study, Cronbach's alpha values for all scales are given for the preintervention administration.
} 
Table 10

Intercorrelation of Medical, Physical, and Psychological Characteristics (Study 5; $N=41$ )

\begin{tabular}{|c|c|c|c|c|c|c|c|c|}
\hline Characteristic & 1 & 2 & 3 & 4 & 5 & 6 & 7 & 8 \\
\hline 1. Stage & - & .18 & -.06 & .02 & .10 & -.15 & .08 & 22 \\
\hline 2. Time since diagnosis & .18 & - & -.25 & -.09 & .20 & -.03 & -.04 & .07 \\
\hline 3. Physical functioning & -.10 & $-.48 * * *$ & - & -.24 & -.26 & -.23 & .11 & .07 \\
\hline 4. Fatigue & .18 & $.35^{*}$ & $-.41 * *$ & - & -.25 & $-.44 * *$ & $.51 * * * *$ & $.58 * * * *$ \\
\hline 5. Pain & .05 & .20 & $-.51 * * *$ & $.54 * * *$ & - & -.10 & $.43 * * *$ & $.53 * * *$ \\
\hline 6. Mindfulness & -.06 & .03 & -.25 & -.18 & -.16 & - & $-.61 * * * *$ & $-.51 * * *$ \\
\hline 7. Mood disturbance & -.05 & .08 & -.12 & $.54 * * *$ & $.46^{* *}$ & $-.43 * *$ & - & $.75^{* * * * *}$ \\
\hline 8. Stress symptoms & .06 & -.01 & -.15 & $.60 * * * *$ & $.51 * * *$ & $-.46^{* *}$ & $.76^{* * * * *}$ & - \\
\hline
\end{tabular}

Note. Values below the diagonal are for Time 1; values above the diagonal are for Time 2. Correlations with cancer stage were based on $n=40$; determination of stage could not be made for one patient.

$* p<.05 . \quad * * p<.01$. **** $p<.001$. **** $p<.0001$.

and duration of cancer were unrelated to the POMS or SOSI at Times 1 and 2, nor was physical functioning as assessed with the EORTC QLQ. Both EORTC QLQ-assessed fatigue and pain were strongly related to POMS and SOSI scores, however, at both points, such that higher symptom levels were related to greater mood disturbance and stress. Fatigue and pain were also positively correlated with each other, but only at Time 1. At both time points, the MAAS was related to lower levels of both mood disturbance and stress.

Multiple regression models were constructed to test the relation between mindfulness and psychological outcomes while controlling for the effects of the two medical variables shown to significantly relate to these outcomes: fatigue and pain. To analyze change across the two time points, residualized change scores were calculated on each predictor and outcome variable (see Cohen \& Cohen, 1983; Judd \& Kenny, 1981). In this pretreatment of the data, Time 2 scores were adjusted for their Time 1 values, so that only variance in residual change in the outcome variables was left to be explained by residual change in the predictors. Table 11 displays these results. The model predicting change in POMS scores was significant, $F(3,40)=4.50, p<.01\left(R^{2}=.27\right)$. Changes in fatigue and pain did not predict change in POMS. However, an increase in MAAS scores from pre- to postintervention predicted a drop in POMS scores $(p<.01)$. Follow-up regression analyses using residuals of each of the POMS subscale scores as dependent variables and the three independent variables used above revealed that an increase in mindfulness was related to a decline in Tension/Anxiety $(p<.05)$, Depression $(p<.01)$, Fatigue $(p<.05)$, and Confusion $(p<.01)$. There was a trend relation between an increase in mindfulness and lowered Anger/ Hostility $(p<.07)$. MAAS change was unrelated to change in Vigor.

Analysis of change in SOSI stress showed that change in Fatigue was unrelated to change in stress. An increase in Pain was marginally predictive of an increase in stress $(p<.10)$. An increase in MAAS scores predicted a decline in stress $(p<.01)$. In both the total POMS and total SOSI models, the MAAS accounted for $14 \%$ of the variance in the pre- to postintervention change. Analyses regressing each of the SOSI subscales on fatigue, pain, and mindfulness showed that an increase in MAAS score predicted declines in stress symptoms related to habitual patterns, anxiety, central nervous system functioning, and muscle tension (all $\mathrm{ps}<.05$ ), as well as depression and cognitive disori- entation (both $p \mathrm{~s}<.01$ ). A marginally significant relation between MAAS score increase and cardiopulmonary stress symptoms decline was also found $(p<.07)$.

Table 11 also shows the results using total POMS and SOSI scores at Times 1 and 2 separately. MAAS score was a significant predictor, in the expected direction, in both POMS and SOSI models at both Time 1 and Time 2 (all $p$ s $<.01$ ). In the Time 1 and Time 2 models, the MAAS explained $10 \%$ and $21 \%$ of the

Table 11

Multiple Regression of Time 1, Time 2, and Pre- to

Postintervention Residual Change in Mood Disturbance and Stress on Fatigue, Pain, and MAAS Scores (Study 5)

\begin{tabular}{cccc}
\hline Predictor & Time 1 & Time 2 & Change \\
\hline \multicolumn{4}{c}{ Mood disturbance } \\
Fatigue & \multicolumn{3}{c}{} \\
$B$ & .48 & .35 & .23 \\
$S E$ & .19 & .29 & .14 \\
$\beta$ & $.37 *$ & .16 & .23 \\
Pain & & & \\
$B$ & .24 & .39 & .18 \\
$S E$ & .17 & .15 & .14 \\
$\beta$ & .21 & .31 & .18 \\
MAAS & & & -.38 \\
$B$ & -14.43 & -27.45 & .14 \\
$S E$ & 5.52 & 6.77 & $-.38^{* *}$ \\
$\beta$ & $-.33^{* *}$ & $-.51^{* * *}$ & \\
\hline
\end{tabular}

Stress

\begin{tabular}{cccc} 
Fatigue & & & \\
$B$ & .93 & .76 & .18 \\
$S E$ & .31 & $.28^{*}$ & .14 \\
$\beta$ & $.41^{* *}$ & .60 & .18 \\
Pain & & .19 & .24 \\
$B$ & .45 & $.38^{* *}$ & .14 \\
$S E$ & .27 & & $.24 \dagger$ \\
$\beta$ & .23 & -23.62 & \\
MAAS & & 8.53 & -.39 \\
$B$ & -26.66 & $-.35^{* *}$ & .14 \\
$S E$ & 8.76 & & $-.39^{* *}$ \\
$\beta$ & $-.35^{* *}$ & & \\
\hline
\end{tabular}

Note. $N=41$. MAAS $=$ Mindful Attention Awareness Scale $\dagger p<.10 . \quad * p<.05 . \quad * * p<.01 . \quad * * * p<.001$. 
variance, respectively, in POMS scores. The MAAS explained $12 \%$ and $10 \%$ of the Time 1 and Time 2 variance, respectively, in total SOSI score.

\section{Discussion}

The results of this clinical intervention study showed that higher levels of mindfulness were related to lower levels of both mood disturbance and stress before and after the MBSR intervention. Increases in mindfulness over the course of the intervention predicted decreases in these two indicators of psychological disturbance. These relations between the MAAS and the outcomes were found after controlling for the influences of fatigue and pain. Such results suggest that the scale can be applied to the study of well-being issues in cancer populations.

It is worth noting that average baseline MAAS scores in this patient sample were higher than in other populations tested. Why these scores were elevated at study entry is an open question, but it would be of interest for future research to determine whether the experience of cancer acts to heighten attention to present-moment experiences and concerns. Evidence has indicated that cancer patients, faced with a life-threatening illness, often reconsider the ways in which they have been living their lives, and many choose to refocus their priorities on existential issues such as personal growth and mindful living (Brennan, 2001).

This study did not include a randomized control group, so the question of the differential effect of training on mindfulness scores between those receiving treatment and those not receiving treatment cannot be answered. However, the present study was not designed to test the efficacy of intervention per se but rather to examine whether mindfulness and changes in it were related to well-being outcomes and changes in them. That said, future research could use the MAAS in a randomized-trials context to test its sensitivity to treatment versus control condition effects. Scores on the MAAS did not change significantly over the 8 weeks of the study, and longer time spans may be necessary to detect changes in this disposition. In this regard, Study 2, presented above, showed that mindfulness practice history (measured in years) was positively associated with MAAS scores.

Finally, the present study focused on a relatively small sample with early-stage prostate and breast cancer. Future research addressing the utility of the MAAS would do well to study larger samples with advanced cancers, among which psychological distress could be higher. The fact that distress is common in patients with a wide variety of acute and chronic medical conditions suggests that the MAAS may also have value in research with other clinical populations.

\section{GENERAL DISCUSSION}

The studies presented in this article were designed to examine the nature of mindfulness and its relation to psychological wellbeing. Initial studies provided evidence for the psychometric adequacy and validity of the Mindful Attention Awareness Scale (MAAS) through exploratory factor analysis and CFA. The MAAS was shown to be a reliable and valid instrument for use in both college student and general adult populations. The MAAS was shown to discriminate between groups expected to differ in degree of mindfulness, and laboratory research provided evidence that mindfulness is associated with heightened self-knowledge, a key element of self-regulation. Correlational studies using the MAAS showed that mindfulness is a distinct form of awareness and attention that is associated with a number of well-being indicators. Finally, experience sampling and clinical studies showed that the MAAS not only predicts well-being outcomes but also has value in the study of the temporal and situational dynamics of selfregulated behavior and well-being.

Much of the current landscape of research on awareness and attention is focused on reflexive consciousness, in which the self is an object of scrutiny or concern (Baumeister, 1999; Kernis, in press). The present research suggests the need to consider forms of consciousness beyond the traditional conceptualizations and measures of self-awareness. As it has been defined here, mindfulness differs from these traditional forms in several ways: Although various forms of self-awareness, as commonly defined, have an inherent cognitive and intellectual foundation, the concept of mindfulness explored here is "prereflexive" in that its foundation is perceptual and nonevaluative. In simple terms, mindfulness is openly experiencing what is there. Although mindfulness includes self-focused attention, it also includes an awareness of one's behavior (cf. Bodner \& Langer, 2001), experience, and the various stimuli encountered as part of waking reality. Finally, although major forms of reflexive consciousness (e.g., private selfconsciousness, rumination) have been shown to have negative consequences for well-being, mindfulness was shown here to relate to and predict more positive well-being and less cognitive and emotional disturbance.

The present research provided empirical support for theoretical perspectives on self-regulation (e.g., Carver \& Scheier, 1981; Ryan \& Deci, 2000) and personality (e.g., Perls, 1973) that carve out a key role for attention and awareness in human health and well-being. We theorized that mindfulness serves an important self-regulatory function. Evidence supporting the self-awareness aspect of self-regulation was provided in a laboratory study showing that the MAAS predicted stronger concordance between implicit and explicit emotional state. Experience-sampling studies with both college student and general adult samples then showed that the MAAS was related to both more autonomous behavioral regulation and emotional well-being at the momentary level. The MAAS predicted state mindfulness in one of these studies, which also revealed substantial within-person variability in moment-tomoment mindfulness. These state variations were themselves predictive of emotional and self-regulatory outcomes. The withinperson variability in mindfulness suggests that there may be identifiable influences on such variation.

The comparison of Zen practitioners with controls suggested that mindfulness can be cultivated by practice. This idea, in combination with many years of observation of the well-being benefits to mindfulness enhancement, has inspired a wide variety of mindfulness-promoting interventions for both medical and general populations. A final study in the present series examined whether changes in MAAS-assessed mindfulness were related to changes in psychological state in a sample of individuals with breast and prostate cancer. In this study, the enhancement of mindfulness was shown to predict declines in both mood disturbance and stress, over and above the effects of changes in physical symptoms.

The MAAS was constructed to be free from attitudinal, motivational, and other psychological phenomena that might have 
contents directly connoting well-being or outcomes closely connected to it (e.g., patience, acceptance). Although the scale was shown to predict a variety of indicators of psychological wellbeing, it does not tap well-being itself and therefore is not confounded with it. In fact, mindfulness, as perceptual presence, is not about achieving well-being; it is purposeless in this sense. As Epstein (2001) argued, an assigned or mandated purpose (to feel good, to be patient, to move past anger, etc.) would only limit an individual's awareness. Such purposive states do not represent being present to what is. Mindfulness, as we conceive it, is present awareness and attention per se- "the ground in which the mind's contents manifest themselves" (Deikman, 1996, p. 351), whatever those contents might be at the moment.

\section{Directions for Future Research}

The study of mindfulness is very much in its infancy, and our results suggest a number of opportunities for further investigation. For example, although the present research found reliable individual differences in mindfulness, the question remains of how this form of consciousness naturally develops and what psychological and social conditions support and hinder its dispositional and state level, or momentary expression. The present research showed that mindfulness can be conceptualized and measured both ways. Research exploring the antecedents and phenomenology of mindful awareness and attention would do much to deepen understanding of the nature of this important phenomenon (cf. Varela \& Shear, 1999). For example, several authors have emphasized the accepting and nonjudgmental nature of mindful awareness and attention (e.g., Bishop, 2002; Kabat-Zinn, 1990). Our conceptualization and measure imply an open receptivity to the present, but this topic deserves further investigation.

The correlational and experience-sampling research reported here found that the trait-level MAAS related more strongly to unpleasant than pleasant affect, whereas state mindfulness was related to both in expected directions. Future research on mindfulness should examine whether this quality of mind is related to self-regulatory processes like mood repair, operationalized as quicker decay rates of unpleasant moods, shorter duration of "bad" moods, and the role of pleasant affect in such repair. A closer look at the affective self-regulatory capacity of mindfulness has important implications for understanding of emotional processes and well-being. More broadly, investigation of the processes by which mindfulness facilitates various self-regulated behaviors and wellbeing outcomes is a logical next step in this research. McIntosh's (1997) integrative review of Zen theory and social psychological research suggested that mindful attention and awareness may have its beneficial effects through insight into present realities, a loosening of attachments to outcomes and to a solid sense of self, and greater clarity in thought and action.

This research focused on the consequences of mindfulness for well-being, but future research could explore the wider scope of application of the MAAS. For example, mindfulness has been proposed to enhance interpersonal behavior (Shapiro \& Schwartz, 1999). As a form of receptive awareness, mindfulness may facilitate the creation of an interval of time or a gap wherein one is able to view one's mental landscape, including one's behavioral options, rather than simply react to interpersonal events. This may make it an important variable in a world where enhanced aware- ness and the consideration of behavioral consequences appear sorely needed. Given these same features, mindfulness may also have influence on behaviors with societal and cultural implications, including those related to drug use and other health behaviors, material consumption, and other lifestyle issues.

\section{Conclusion}

The intent of this program of studies was to demonstrate the role of mindfulness, measured in both inter- and intraindividual terms, in psychological well-being. Interest in the underpinnings and enhancement of well-being has been burgeoning in recent years (e.g., Ryan \& Deci, 2001; Seligman \& Csikszentmihalyi, 2000). Our hope is that the present research nourishes this trend, because it indicates that mindfulness is a reliably and validly measured characteristic that has a significant role to play in a variety of aspects of mental health. Further research into this attribute may open up significant new avenues for well-being enhancement.

\section{References}

Aaronson, N. K., Ahmedzai, S., Bergman, B., Bullinger, M., Cull, A., Duez, N. J., et al. (1993). The European Organization for Research and Treatment of Cancer QLQ-C30: A quality-of-life instrument for use in international clinical trials in oncology. Journal of the National Cancer Institute, 85, 365-376.

Aiken, L. A. (1985). Three coefficients for analyzing the reliability and validity of ratings. Educational and Psychological Measurement, 45, 131-142.

Aiken, L. A. (1996). Rating scales and checklists: Evaluating behavior, personality, and attitudes. New York: Wiley.

Aiken, L. S., \& West, S. G. (1991). Multiple regression: Testing and interpreting interactions. Newbury Park, CA: Sage.

American Psychiatric Association. (1994). Diagnostic and statistical manual of mental disorders (4th ed.). Washington, DC: Author.

Arbuckle, J. L., \& Wothke, W. (1999). Amos 4.0 user's guide. Chicago: SmallWaters Corporation.

Astin, J. A. (1997). Stress reduction through mindfulness meditation. Psychotherapy and Psychosomatics, 66, 97-106.

Averill, J. R. (1992). The structural bases of emotional behavior: A metatheoretical analysis. Review of Personality and Social Psychology, 13, 1-24.

Bargh, J. A. (1997). Automaticity in social psychology. In E. T. Higgins \& A. W. Kruglanski (Eds.), Social psychology: Handbook of basic principles (pp. 109-183). New York: Guilford Press.

Bargh, J. A., \& Ferguson, M. J. (2000). Beyond behaviorism: On the automaticity of higher mental processes. Psychological Review, 126, 925-945.

Basilevsky, A. (1994) Statistical factor analysis and related methods: Theory and applications. New York: Wiley.

Basmajian, J. V. (1989). Biofeedback: Principles and practice for clinicians (3rd ed.). Baltimore: William \& Wilkins.

Baumeister, R. F. (1991). Escaping the self: Alcoholism, spirituality, masochism, and other flights from the burden of selfhood. New York: Basic Books.

Baumeister, R. F. (1999). The nature and structure of the self: An overview. In R. F. Baumeister (Ed.), The self in social psychology (pp. 1-20). Philadelphia: Psychology Press.

Baumeister, R. F., Heatherton, T. F., \& Tice, D. M. (1994). Losing control: How and why people fail at self-regulation. San Diego, CA: Academic Press.

Beckham, E. E., \& Leber, W. (Eds.). (1985). Handbook of depression: Treatment, assessment, and research. Homewood, IL: Dorsey. 
Bermúdez, J. L. (1998). The paradox of self-consciousness. Cambridge, MA: MIT Press.

Bishop, S. R. (2002). What do we really know about mindfulness-based stress reduction? Psychosomatic Medicine, 64, 71-83.

Bodner, T. E., \& Langer, E. J. (2001, June). Individual differences in mindfulness: The Mindfulness/Mindlessness Scale. Poster presented at the 13th annual American Psychological Society Convention, Toronto, Ontario, Canada.

Bowerman, B. L., \& O'Connell, R. T. (1993). Forecasting and time-series (3rd ed.). Belmont, CA: Duxbury.

Brazier, D. (1995). Zen therapy: Transcending the sorrows of the human mind. New York: Wiley.

Brennan, J. (2001). Adjustment to cancer: Coping or personal transition? Psycho-Oncology, 10, 1-18.

Brown, K. W. (1998). Emotional body, physical mind: An exploration of the psychosomatic system through the lens of day-to-day experience. Unpublished doctoral dissertation, McGill University, Montreal, Quebec, Canada.

Brown, K. W., \& Kasser, T. (2002). Integrating psychological and ecological well-being: The role of values and lifestyle. Unpublished data, University of Rochester.

Brown, K. W., Kasser, T., Ryan, R. M., \& Konow, J. (2002). To have or to be: Investigating the pathways from materialism and mindfulness to psychological well-being. Manuscript in preparation, University of Rochester.

Brown, K. W., \& Moskowitz, D. S. (1997). Does unhappiness make you sick? The role of affect and neuroticism in the experience of common physical symptoms. Journal of Personality and Social Psychology, 72, 907-917.

Brown, K. W., \& Moskowitz, D. S. (1998). Dynamic stability of behavior: The rhythms of our interpersonal lives. Journal of Personality, 66, 105-134.

Bryk, A. S., \& Raudenbush, S. W. (1992). Hierarchical linear models: Applications and data analysis methods. Newbury Park, CA: Sage.

Buss, A. H. (1980). Self-consciousness and social anxiety. San Francisco: Freeman.

Cacioppo, J. T., Petty, R. E., \& Kao, C. F. (1984). The efficient assessment of need for cognition. Journal of Personality Assessment, 48, 306-307.

Carlson, L. E., Ottenbreit, N., St. Pierre, M., \& Bultz, B. D. (2001). Partner understanding of the breast and prostate cancer experience. Cancer Nursing, 24, 231-239.

Carlson, L. E., Ursuliak, Z., Goodey, E., Angen, M., \& Speca, M. (2001). The effects of a mindfulness meditation-based stress reduction program on mood and symptoms of stress in cancer outpatients: 6-month followup. Supportive Care in Cancer, 9, 112-123.

Carver, C. S., \& Scheier, M. F. (1981). Attention and self-regulation: A control-theory approach to human behavior. New York: SpringerVerlag.

Cassileth, B. R., Lusk, E. J., Brown, L. L., \& Cross, P. A. (1985). Psychosocial status of cancer patients and next of kin: Normative data from the Profile of Mood States. Journal of Psychosocial Oncology, 3, 99-105.

Clark, D. M. (1986). A cognitive model of panic. Behaviour Research and Therapy, 24, 461-470.

Cohen, J., \& Cohen, P. (1983). Applied multiple regression/correlation analysis for the behavioral sciences (2nd ed.). Hillsdale, NJ: Erlbaum.

Costa, P. T., Jr., \& McCrae, R. R. (1992). Revised NEO Personality Inventory (NEO PI-R) and NEO Five-Factor Inventory (NEO-FFI): Professional manual. Odessa, FL: Psychological Assessment Resources.

Cramer, K. M. (2000). Comparing the relative fit of various factor models of the Self-Consciousness Scale in two independent samples. Journal of Personality Assessment, 75, 295-307.

Creed. A. T., \& Funder, D. C. (1998). The two faces of private self- consciousness: Self-report, peer-report, and behavioral correlates. European Journal of Personality, 12, 411-431.

Crowne, D. P., \& Marlowe, D. (1960). A new scale of social desirability independent of psychopathology. Journal of Consulting Psychology, 24, $349-354$.

Csikszentmihalyi, M. (1990). Flow: The psychology of optimal experience. New York: HarperCollins.

Cudeck, R. (2000). Exploratory factor analysis. In H. E. A. Tinsley \& S. D. Brown (Eds.), Handbook of applied multivariate statistics and mathematical modeling (pp. 266-296). San Diego, CA: Academic Press.

Cunningham, W. A., Preacher, K. J., \& Banaji, M. R. (2001). Implicit attitude measures: Consistency, stability and convergent validity. Psychological Science, 12, 163-170.

Davis, M. H., \& Franzoi, S. L. (1999). Self-awareness and selfconsciousness. In V. J. Derlega, B. A. Winstead, \& W. H. Jones (Eds.), Personality: Contemporary theory and research (2nd ed., pp. 307-338). Chicago: Nelson-Hall.

Dawis, R. V. (2000). Scale construction and psychometric considerations. In H. E. A. Tinsley \& S. D. Brown (Eds.), Handbook of applied multivariate statistics and mathematical modeling (pp. 65-94). San Diego, CA: Academic Press.

Deci, E. L., \& Ryan, R. M. (1980). Self-determination theory: When mind mediates behavior. The Journal of Mind and Behavior, 1, 33-43.

Deci, E. L., \& Ryan, R. M. (1985). Intrinsic motivation and selfdetermination in human behavior. New York: Plenum Press.

DeFlorio, M., \& Masie, M. J. (1995). Review of depression in cancer: Gender differences. Depression, 3, 66-80.

DeHart, T., \& Pelham, B. W. (2002, February). Are explicit and implicit self-esteem always uncorrelated? Paper presented at the 3rd annual meeting of the Society for Personality and Social Psychology, Savannah, GA.

Deikman, A. J. (1982). The observing self. Boston: Beacon Press.

Deikman, A. J. (1996). "I" = awareness. Journal of Consciousness Studies, 3, 350-356

Derogatis, L. R., Lipman, R. S., Rickels, K., Uhlenhuth, E. H., \& Covi, L. (1974). The Hopkins Symptom Checklist (HSCL): A self-report symptom inventory. Behavioral Science, 19, 1-15.

Diener, E., \& Emmons, R. A. (1984). The independence of positive and negative affect. Journal of Personality and Social Psychology, 47, 1105-1117.

Diener, E., Sandvik, E., Pavot, W., \& Gallagher, D. (1991). Response artifacts in the measurement of subjective well-being. Social Indicators Research, 24, 35-56.

Diener, E., Suh, E. M., Lucas, R. E., \& Smith, H. L. (1999). Subjective well-being: Three decades of progress. Psychological Bulletin, 2, 276302.

Duval, S., \& Wicklund, R. A. (1972). A theory of objective selfconsciousness. New York: Academic Press.

Epstein, R. M. (2001). Just being. Western Journal of Medicine, 174, 63-65.

Farnham, S. D., Greenwald, A. G., \& Banaji, M. R. (1998). Implicit self-esteem. In D. Abrams \& M. A. Hogg (Eds.), Social cognition and social identity (pp. 230-248). London: Blackwell.

Fejfar, M. C., \& Hoyle, R. H. (2000). Effect of private self-awareness on negative affect and self-referent attribution: A quantitative review. Personality and Social Psychology Review, 4, 132-142.

Fenigstein, A., Scheier, M. F., \& Buss, A. H. (1975). Public and private self-consciousness: Assessment and theory. Journal of Consulting and Clinical Psychology, 43, 522-527.

Fisher, R. A. (1928). Statistical methods for research workers (2nd ed.). London: Oliver \& Boyd.

Flory, J. D., Raikkonen, K., Matthews, K. A., \& Owens, J. F. (2000). Self-focused attention and mood during everyday social interactions. Personality and Social Psychology Bulletin, 26, 875-883. 
Freud, S. (1963). Recommendations for physicians on the psycho-analytic method of treatment. In P. Reiff (Ed.), Freud: Therapy and technique (pp. 117-126). New York: Collier. (Original work published 1912)

Gemar, M. C., Segal, Z. V., Sagrati, S., \& Kennedy, S. J. (2001). Moodinduced changes on the Implicit Association Test in recovered depressed patients. Journal of Abnormal Psychology, 110, 282-289.

Goldman, S. L., Kraemer, D. T., \& Salovey, P. (1996). Beliefs about mood moderate the relationship of stress to illness and symptom reporting. Journal of Psychosomatic Research, 41, 115-128.

Goldstein, J. (1987). The experience of insight. Boston: Shambhala.

Gotay, C. C., \& Stern, J. D. (1995). Assessment of psychological functioning in cancer patients. Journal of Psychosocial Oncology, 13, 123160.

Greenwald, A. G., \& Banaji, M. R. (1995). Implicit social cognition: Attitudes, self-esteem, and stereotypes. Psychological Review, 102, $4-27$.

Greenwald, A. G., \& Farnham, S. D. (2000). Using the implicit association test to measure self-esteem and self-concept. Journal of Personality and Social Psychology, 79, 1022-1038.

Greenwald, A. G., McGhee, D. E., \& Schwartz, J. L. K. (1998). Measuring individual differences in implicit cognition: The implicit association test. Journal of Personality and Social Psychology, 74, 1464-1480.

Hanh, T. N. (1976). Miracle of mindfulness. Boston: Beacon.

Hathaway, S. R., \& McKinley, J. C. (1989). Minnesota Multiphasic Personality Inventory-2. Minneapolis: University of Minnesota Press.

Haynes, R. B., Taylor, D. W., Sackett, D. L., Gibson, E. S. Bernholz, C. D., \& Mukherjee, J. (1980). Can simple clinical measurements detect patient noncompliance? Hypertension, 2, 757-764.

Hodgins, H. S., \& Knee, C. R. (2002). The integrating self and conscious experience. In E. L. Deci \& R. M. Ryan (Eds.), Handbook of selfdetermination research (pp. 87-100). Rochester, NY: University of Rochester Press.

Hoyle, R. H. (2000). Confirmatory factor analysis. In H. E. A. Tinsley \& S. D. Brown (Eds.), Handbook of applied multivariate statistics and mathematical modeling (pp. 466-497). San Diego, CA: Academic Press.

James, W. (1924). Memories and studies. New York: Longmans, Green, \& Co. (Original work published 1911)

Judd, C. M., \& Kenny, D. A. (1981). Estimating the effects of social interventions. London: Cambridge University Press.

Kabat-Zinn, J. (1990). Full catastrophe living: Using the wisdom of your body and mind to face stress, pain, and illness. New York: Delacourt.

Kabat-Zinn, J., Lipworth, L., \& Burney, R. (1985). The clinical use of mindfulness meditation for the self-regulation of chronic pain. Journal of Behavioral Medicine, 8, 162-190.

Kabat-Zinn, J., Massion, A. O., Kristeller, J., Peterson, L. G., Fletcher, K. E., Pbert, L., et al. (1992). Effectiveness of a meditation-based stress reduction program in the treatment of anxiety disorders. American Journal of Psychiatry, 149, 936-943.

Keller, M., \& Henrich, G. (1999). Illness-related distress: Does it mean the same for men and women? Acta Oncologica, 38, 747-755.

Kernis, M. H. (in press). Toward a conceptualization of optimal selfesteem. Psychological Inquiry.

Kreft, I., \& deLeeuw, J. (1998). Introducing multilevel modeling. Thousand Oaks, CA: Sage.

La Guardia, J., Ryan, R. M., Couchman, C. E., \& Deci, E. L. (2000). Within-person variation in security of attachment: A self-determination theory perspective on attachment, need fulfillment, and well-being. Journal of Personality and Social Psychology, 79, 367-384.

Langer, E. J. (1989). Mindfulness. Reading, MA: Addison Wesley.

Langer, E. J., \& Moldoveanu, M. (2000). The construct of mindfulness. Journal of Social Issues, 56, 1-9.

Larsen, R. J., \& Kasimatis, M. (1991). Day-to-day physical symptoms:
Individual differences in the occurrence, duration, and emotional concomitants of minor daily illnesses. Journal of Personality, 59, 387-423.

LeBel, J. L., \& Dubé, L. (2001, June). The impact of sensory knowledge and attentional focus on pleasure and on behavioral responses to hedonic stimuli. Paper presented at the 13th annual American Psychological Society Convention, Toronto, Ontario, Canada.

Leckie, M. S., \& Thompson, E. (1979). Symptoms of Stress Inventory. Seattle: University of Washington.

Lefrançois, R., Leclerc, G., Dubé, M., Hébert, R., \& Gaulin, P. (1997). The development and validation of a self-report measure of selfactualization. Social Behavior and Personality, 25, 353-365.

Levesque, C. S., \& Brown, K. W. (2002). Mindful awareness as a moderator of the relationship between implicit and explicit motives. Manuscript in preparation.

Linehan, M. M, Cochran, B. N., \& Kehrer, C. A. (2001). Dialectical behavior therapy for borderline personality disorder. In D. H. Barlow (Ed.), Clinical handbook of psychological disorders: A step-by-step treatment manual (3rd ed., pp. 470-522). New York: Guilford Press.

Litt, M. D., Cooney, N. L., \& Morse, P. (1998). Ecological momentary assessment (EMA) with treated alcoholics: Methodological problems and potential solutions. Health Psychology, 17, 48-52.

Maddux, J. E. (1997). Habit, health and happiness. Journal of Sport and Exercise Psychology, 19, 331-346.

Martin, J. R. (1997). Mindfulness: A proposed common factor. Journal of Psychotherapy Integration, 7, 291-312.

Mayer, J. D. (2000). Spiritual intelligence or spiritual consciousness. The International Journal for the Psychology of Religion, 10, 47-56.

Mayer, J. D., Chabot, H. F., \& Carlsmith, K. (1997). Conation, affect, and cognition in personality. In G. Matthews (Ed.), Cognitive science perspectives on personality and emotion (pp. 31-63). Amsterdam: Elsevier.

McIntosh, W. D. (1997). East meets West: Parallels between Zen Buddhism and social psychology. International Journal for the Psychology of Religion, 7, 37-52.

McNair, D. M., Lorr, M., \& Droppleman, L. F. (1971). Profile of mood states. San Diego, CA: Educational and Industrial Testing Service.

National Cancer Institute of Canada. (2001). Canadian cancer statistics 2001. Retrieved April 20, 2002, from http://66.59.133.166/stats/tables/ table.htm

Nolen-Hoeksema, S., Morrow, J., \& Fredrickson, B. L. (1993). Response styles and the duration of episodes of depressed mood. Journal of Abnormal Psychology, 102, 20-28.

Nordin, K., Berglund, G., Glimelius, B., \& Sjoden, P. O. (2001). Predicting anxiety and depression among cancer patients: A clinical model. European Journal of Cancer, 37, 376-384.

Nyanaponika Thera. (1972). The power of mindfulness. San Francisco, CA: Unity Press.

O'Brien, E. J., \& Epstein, S. (1988). MSEI: The Multidimensional SelfEsteem Inventory: Professional manual. Odessa, FL: Psychological Assessment Resources.

Packer, T. (2002). The wonder of presence. Boston: Shambhala.

Pavot, W., Diener, E., \& Suh, E. (1998). The Temporal Satisfaction With Life Scale. Journal of Personality Assessment, 70, 340-354.

Perls, F. (1973). The gestalt approach and eye witness to therapy. New York: Bantam Books.

Radloff, L. S. (1977). The CES-D Scale: A self-report depression scale for research in the general population. Applied Psychological Measurement, 1, 385-401.

Reibel, D. K., Greeson, J. M., Brainard, G. C., \& Rosenzweig, S. (2001). Mindfulness-based stress reduction and health-related quality of life in a heterogeneous patient population. General Hospital Psychiatry, 23, 183-192.

Reis, H. T., Sheldon, K. M., Gable, S. L., Roscoe, J., \& Ryan, R. M. (2000) Daily well-being: The role of autonomy, competence, and relatedness. Personality and Social Psychology Bulletin, 26, 419-435. 
Rosenberg, M. (1965). Society and the adolescent self-image. Princeton, NJ: Princeton University Press.

Rosenthal, R. (1991). Meta-analytic procedures for social research (Rev. ed.). Newbury Park, CA: Sage.

Ryan, R. M., \& Connell, J. (1989). Perceived locus of causality and internalization: Examining reasons for acting in two domains. Journal of Personality and Social Psychology, 57, 749-761.

Ryan, R. M., \& Deci, E. L. (2000). Self-determination theory and the facilitation of intrinsic motivation, social development, and well-being. American Psychologist, 55, 68-78.

Ryan, R. M., \& Deci, E. L. (2001). On happiness and human potentials: A review of research on hedonic and eudaimonic well-being. Annual Review of Psychology, 52, 141-166.

Ryan, R. M., \& Frederick, C. (1997). On energy, personality, and health: Subjective vitality as a dynamic reflection of well-being. Journal of Personality, 65, 529-565.

Ryan, R. M., Kuhl, J., \& Deci, E. L. (1997). Nature and autonomy: An organizational view of social and neurobiological aspects of selfregulation in behavior and development. Development and Psychopathology, 9, 701-728.

Ryff, C. (1989). Happiness is everything, or is it? Explorations on the meaning of psychological well-being. Journal of Personality and Social Psychology, 57, 1069-1081.

Safran, J. D., \& Segal, Z. V. (1990). Interpersonal process in cognitive therapy. New York: Basic Books.

Salovey, P., Mayer, J. D., Goldman, S. L., Turvey, C., \& Palfai, T. F. (1995). Emotional attention, clarity, and repair: Exploring emotional intelligence using the Trait Meta-Mood Scale. In J. W. Pennebaker (Ed.), Emotion, disclosure, and health (pp. 125-154). Washington, DC: American Psychological Association.

SAS Institute. (1992). SAS/STAT software: Changes and enhancements (SAS Tech. Rep. P-229). Cary, NC: Author.

SAS Institute. (1997). SAS/STAT software: Changes and enhancements through release 6.12. Cary, NC: Author.

Scheier, M. F., \& Carver, C. S. (1985). Optimism, coping, and health: Assessment and implications of generalized outcome expectancies. Health Psychology, 4, 219-247.

Schneider, W., Eschman, A., \& Zuccolotto, A. (2002). E-Prime user's guide. Pittsburgh, PA: Psychology Software Tools.

Schultheiss, O. C., \& Brunstein, J. C. (1999). Goal imagery: Bridging the gap between implicit motives and explicit goals. Journal of Personality, 67, 1-38.

Schumacker, R. E., \& Lomax, R. G. (1996). A beginner's guide to structural equation modeling. Mahwah, NJ: Erlbaum.

Schwartz, G. E. (1984). Psychobiology of health: A new synthesis. In B. L. Hammonds \& J. Scheirer (Eds.), Psychology and health: Master lecture series (Vol. 3, pp. 149-193). Washington, DC: American Psychological Association.

Schwartz, J. E., \& Stone, A. A. (1998). Strategies for analyzing ecological momentary assessment data. Health Psychology, 17, 6-16.

Seligman, M. E. P., \& Csikszentmihalyi, M. (2000). Positive psychology: An introduction. American Psychologist, 55, 5-14.

Sellick, S. M., \& Crooks, D. L. (1999). Depression and cancer: An appraisal of the literature for prevalence, detection, and practice guideline development for psychological interventions. Psycho-Oncology, 8, 315-333.

Shapiro, S. L., \& Schwartz, G. E. R. (1999). Intentional systemic mindfulness: An integrative model for self-regulation and health. Advances in Mind-Body Medicine, 15, 128-134.

Shapiro, S. L., Schwartz, G. E., \& Bonner, G. (1998). Effects of mindfulness-based stress reduction on medical and premedical students. Journal of Behavioral Medicine, 21, 581-599.

Shear, J., \& Jevning, R. (1999). Pure consciousness: Scientific exploration of meditation techniques. In F. J. Varela \& J. Shear (Eds.), The view from within (pp. 189-209). Thorverton, England: Imprint Academics.

Sheard, T., \& Maguire, P. (1999). The effect of psychological interventions on anxiety and depression in cancer patients: Results of two metaanalyses. British Journal of Cancer, 80, 1770-1780.

Sheldon, K. M., Ryan, R. M., Rawsthorne, L. J., \& Ilardi, B. (1997). Trait self and true self: Cross-role variation in the Big-Five personality traits and its relations with psychological authenticity and subjective wellbeing. Journal of Personality and Social Psychology, 73, 1380-1393.

Sheldon, K. M., Ryan, R. M., \& Reis, H. T. (1996). What makes for a good day? Competence and autonomy in the day and in the person. Personality and Social Psychology Bulletin, 22, 1270-1279.

Shevrin, H. (2000). The experimental investigation of unconscious conflict, unconscious affect, and unconscious signal anxiety. In M. Velmans (Ed.), Investigating phenomenal consciousness: New methodologies and maps (pp. 33-65). Philadelphia: John Benjamins.

Shiffman, S. (2000). Real time self-report of momentary states in the natural environment: Computerized ecological momentary assessment. In A. A. Stone, J. S. Turkkan, C. A. Bachrach, J. B. Jobe, H. S. Kurtzman, \& V. S. Cain (Eds.), The science of self-report: Implications for research and practice (pp. 277-296). Mahwah, NJ: Erlbaum.

Singer, J. D. (1998). Using SAS PROC MIXED to fit multilevel models, hierarchical models, and individual growth models. Journal of Educational and Behavioral Statistics, 23, 323-356.

Snyder, M. (1974). Self-monitoring of expressive behavior. Journal of Personality and Social Psychology, 30, 526-537.

Snyder, M., \& Gangestad, S. (1986). The nature of self-monitoring. Journal of Personality and Social Psychology, 51, 125-129.

Speca, M., Carlson, L. E., Goodey, E., \& Angen, M. (2000). A randomized, wait-list controlled clinical trial: The effect of a mindfulness meditationbased stress reduction program on mood and symptoms of stress in cancer outpatients. Psychosomatic Medicine, 62, 613-622.

Spiegel, D. (1996). Cancer and depression. British Journal of Psychiatry, 168(Suppl. 30), 109-116.

Spielberger, C. D. (1983). Manual for the State-Trait Anxiety Inventory: STAI (Form Y). Palo Alto, CA: Consulting Psychologists Press.

Tabachnick, B. G., \& Fidell, L. S. (1996). Using multivariate statistics (3rd ed.). Boston: Allyn \& Bacon.

Tart, C. T. (1994). Living the mindful life. Boston: Shambhala.

Teasdale, J. D., Segal, Z. V., Williams, J. M. G., Ridgeway, V. A., Soulsby, J. M., \& Lau, M. A. (2000). Prevention of relapse/recurrence in major depression by mindfulness-based cognitive therapy. Journal of Consulting and Clinical Psychology, 68, 615-625.

Tellegen, A. (1982). Brief manual for the multidimensional personality questionnaire. Unpublished manuscript, University of Minnesota.

Thrash, T., \& Elliot, A. (2002). Implicit and self-attributed achievement motives: Concordance and predictive validity. Journal of Personality, 70, 729-755

Trapnell, P. D., \& Campbell, J. (1999). Private self-consciousness and the five-factor model of personality: Distinguishing rumination from reflection. Journal of Personality and Social Psychology, 76, 284-304.

Varela, F. J., \& Shear, J. (1999). First-person methodologies: What, why, how? In F. J. Varela \& J. Shear (Eds.), The view from within (pp. 1-14). Thorverton, England: Imprint Academics.

Varela, F. J., Thompson, E., \& Rosch, E. (1991). The embodied mind: Cognitive science and human experience. Cambridge, MA: MIT Press.

Velikova, G., Wright, P., Smith, A. B., Stark, D., Perren, T., Brown, J., \& Selby, P. (2001). Self-reported quality of life of individual cancer patients: Concordance of results with disease course and medical records. Journal of Clinical Oncology, 19, 2064-2073.

Waldrup, M. M. (1992). Complexity: The emerging science at the edge of order and chaos. New York: Simon \& Schuster.

Wallace, B. A. (1999). The Buddhist tradition of samantha: Methods for refining and examining consciousness. In F. J. Varela \& J. Shear (Eds.), 
The view from within (pp. 175-187). Thorverton, England: Imprint Academics.

Watson, D., Clark, L. A., \& Tellegen, A. (1988). Development and validation of brief measures of positive and negative affect: The PANAS scales. Journal of Personality and Social Psychology, 54, 1063-1070.

West, S. G., \& Hepworth, J. T. (1991). Statistical issues in the study of temporal data: Daily experiences. Journal of Personality, 59, 611-661.

Westen, D. (1998). Unconscious thought, feeling and motivation: The end of a century-long debate. In R. F. Bornstein \& J. M. Mesling (Eds.), Empirical perspectives on the psychoanalytic unconscious (pp. 1-43). Washington, DC: American Psychological Association.

Westen, D. (1999). Psychology: Mind, brain, and culture (2nd ed). New York: Wiley.

Wilber, K. (2000). Integral psychology: Consciousness, spirit, psychology, therapy. Boston: Shambhala.
Wild, K. P. (1999). Time sampling procedures with Random 2.1: Introduction and user's guide. Neubiberg, Germany: University of the Armed Forces, Munich.

Williams, K. A., Kolar, M. M., Reger, B. E., \& Pearson, J. C. (2001) Evaluation of a wellness-based mindfulness stress reduction intervention: A controlled trial. American Journal of Health Promotion, 15, 422-432.

Wilson, T. D., Lindsey, S., \& Schooler, T. Y. (2000). A model of dual attitudes. Psychological Review, 107, 101-126.

Received May 20, 2002 Revision received August 19, 2002

Accepted September 24, 2002

\section{Low Publication Prices for APA Members and Affiliates}

Keeping you up-to-date. All APA Fellows, Members, Associates, and Student Affiliates receive-as part of their annual dues-subscriptions to the American Psychologist and APA Monitor. High School Teacher and International Affiliates receive subscriptions to the APA Monitor, and they may subscribe to the American Psychologist at a significantly reduced rate. In addition, all Members and Student Affiliates are eligible for savings of up to $60 \%$ (plus a journal credit) on all other APA journals, as well as significant discounts on subscriptions from cooperating societies and publishers (e.g., the American Association for Counseling and Development, Academic Press, and Human Sciences Press).

Essential resources. APA members and affiliates receive special rates for purchases of APA books, including the Publication Manual of the American Psychological Association, and on dozens of new topical books each year.

Other benefits of membership. Membership in APA also provides eligibility for competitive insurance plans, continuing education programs, reduced APA convention fees, and specialty divisions.

More information. Write to American Psychological Association, Membership Services, 750 First Street, NE, Washington, DC 20002-4242. 